2015-03-06

\title{
Potential of Biofluid Components to Modify Silver Nanoparticle Toxicity
}

\author{
Gordon Chambers \\ Technological University Dublin, Gordon.chambers@tudublin.ie \\ Anna Murphy \\ Technological University Dublin, ann.murphy3@tudublin.ie \\ Kate Sheehy \\ Technological University Dublin
}

See next page for additional authors

Follow this and additional works at: https://arrow.tudublin.ie/scschphyart

Part of the Life Sciences Commons

\section{Recommended Citation}

Chambers, G. et al. (2015) Potential of Biofluid components to modify Silver Nanoparticle Toxicity Journal of Applied Toxicology 35 (6), 665-680. doi:10.1002/jat.3123

This Article is brought to you for free and open access by the School of Physics \& Clinical \& Optometric Science at ARROW@TU Dublin. It has been accepted for inclusion in Articles by an authorized administrator of ARROW@TU

Dublin. For more information, please contact

arrow.admin@tudublin.ie, aisling.coyne@tudublin.ie, gerard.connolly@tudublin.ie.

Funder: SCIENCE FUNDATION IRELAND

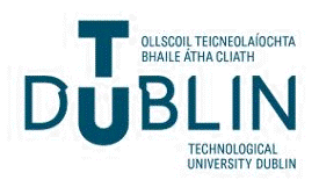


Authors

Gordon Chambers, Anna Murphy, Kate Sheehy, and Alan Casey

This article is available at ARROW@TU Dublin: https://arrow.tudublin.ie/scschphyart/61 


\title{
Potential of Biofluid components to modify Silver Nanoparticle Toxicity
}

\author{
A. Murphy*1, K. Sheehy1, A. Casey1, G. Chambers1, 2 \\ 1. Nanolab Research Centre, Focas Institute, Dublin Institute of Technology, Kevin \\ Street, Dublin 8, Ireland \\ 2. School of Physics, Dublin Institute of Technology, Kevin Street, Dublin 8, Ireland
}

*Corresponding Author E-mail: anna.murphy3 @ mydit.ie Ph: +35314027932 Fax:

+35314027901 .

\begin{abstract}
Establishing realistic exposure scenarios is critical for cytotoxic investigation of silver (Ag) nanoparticles in the gastrointestinal tract. This study investigated the potential interaction with and effect of biofluid components, namely cholic acid, deoxycholic acid and ursodeoxycholic acid, on AgNP toxicity. Two cell lines corresponding to organs related to the biofluid components were employed. These were HepG-2 a hepatocellular carcinoma derived from liver tissue and Hep2 an epithelial cell line. Physiochemical and cytotoxic screening was performed and the ability of biofluid components to modify AgNP cytotoxicity was explored. No alteration to the physiochemical characteristics of AgNP by biofluid components was demonstrated. However, biofluid component addition resulted in alteration of AgNP toxicity. Greater ROS induction was noted in the presence of CA and DCA. UDCA demonstrated no modification of toxicity in HEpG2 cells however significant modification was noted in Hep2 cells. It is concluded that biofluid components can modify AgNP toxicity but this is dependent on the biofluid component itself and the location where it acts.
\end{abstract}

\section{Short Abstract}

Silver nanoparticle (AgNP) interaction with biofluids upon entry to the body is important for accurate toxicological investigation. A number of toxicological tests were performed and demonstrated modification of AgNP toxicity by the chosen biofluid components cholic acid, deoxycholic acid and ursodeoxycholic acid. It is concluded that the influence on AgNP toxicity by biofluid components is dependent on the biofluid component itself and the location where it acts.

\section{Introduction}

Nanotechnology has been described as a new frontier in science and technology with many different applications in fields including textiles, electronics, medicine, cosmetics and food (Sozar \& Kokini, 2009; Bouwmeester et al, 2009). Silver (AgNP) nanoparticles in particular are becoming the material of choice for incorporation into consumer goods mainly due to their antimicrobial properties (Choi et al, 2008). Compared to bulk silver, nanosilver displays different 
physiochemical properties due to its size and increased surface area including increased photonics and catalytic properties as well as enhanced antimicrobial activity (Choi et al, 2008; Poda et al, 2011; Zhai et al, 2006).

When considering nanoparticle exposure it is important to take into account not only the route of entry to the body but also the various biological systems, biofluids and surfactants they will encounter. Indeed as a result of the potential interaction with the various components of bio-fluids, nanoparticles may be affected ultimately changing how they interact with cells and the responses they evoke.

With the ever increasing use of nanoparticles in food products and with new EU legislation enforcing that all forms of engineered nanoparticles present in food must be stated on food packaging, "nano-labeling" coming into effect in December 2014, it is now more crucial than ever that the interaction between nanoparticles and living systems is thoroughly investigated (Nano and other Emerging Technologies Blog, 2013). In particular, the potential toxic effect of nanoparticles to the gastrointestinal tract and their interactions with various biofluids associated with this system must be determined.

The gastrointestinal tract has been noted as a major area of AgNP deposition coupled with pathological responses. A number of studies have demonstrated damaged microvilli and intestinal glands, abnormal pigmentation and an increase in intestinal goblet cells following oral administration of AgNP in rats (Hadrup \& Lam, 2014; Shahare \& Yashpal, 2013; Jeong et al, 2010; Kim et al, 2010). The liver in particular is an important site of nanoparticle deposition following oral ingestion with reports of high concentrations of AgNP reported in mice 24 hours after exposure. Inhalation also provides a route to the liver. Mucocilliary clearance of nanoparticles can result in entry to the GI tract and deposition in the liver. Accumulation of AgNP can lead to liver toxicity including bile duct hyperplasia and inflammation (Kim et al, 2008; Nemmar et al, 2002). The liver has also been identified as a one of the main pathways involved in nanoparticle excretion. Hepato-biliary secretion is believed to be a main route of intestinal secretion of nanoparticles with evidence of gold and polystyrene nanoparticle excretion by this route. Accumulation of nanoparticles within bile canaliculi is suggestive of the important role of bile in the intestinal secretion and elimination of nanoparticles in faeces (Zhao et al, 2014; Johnston et al, 2010; Semmler-Behnke et al, 2008).

A biofluid is any fluid originating from within the body that can be excreted, secreted, obtained by a needle or can develop due to a pathological process and ranges from blood to bile and breast milk to cyst fluid (Medicinenet). It has been shown that certain biofluids and surfactants can aid the processing of nanoparticles and can isolate nanoparticles from larger agglomerates by coating the particle or modifying its surface chemistry (Herzog et al, 2009). Interactions with various surfactants including biological surfactants and fluids can result in adsorption of a variety of different molecules and proteins onto the surface of nanoparticles. As a result many studies have shown that this "coating" can affect how a nanoparticle interacts with the biological environment. These affects range from changes in the particle itself such as ion release and changes in morphology to the responses it induces and where it is trafficked within the body (Herzog et al, 2009; Mwilu et al, 2013; Ehrenberg et al, 2009; Wang et al, 2013; Misra et al, 2012; Aggarwal et $a l, 2009)$. It is this ability of biofluids to interact and process foreign bodies in the human body 
that make them integral to the defence systems of the body. In this study three components of bile were chosen and are referred to as biofluid components throughout as they were studied individually. The biofluid components employed were cholic acid (CA), deoxycholic acid (DCA) and ursodeoxycholic acid (UDCA).

Bile salts are organic solutes synthesized from cholesterol by hepatocytes (Kumar \& Bohidar, 2010; Perez \& Briz, 2009). Cholic acid is one of the major primary bile acids in the liver and is synthesized from cholesterol and constitutes about 30-40\% of bile acids (Debruyne et al, 2001). Formation of these bile acids is important in cholesterol homeostasis. Deoxycholic acid is a secondary bile acid and constitutes roughly 10-40\% of total bile (Marcus \& Heaton, 1988). DCA has also been demonstrated to promote colonic epithelium proliferation (Deschner et al, 1981; Ochsenkuhn et al, 1999). UDCA is a secondary bile acid comprising 3\% of total bile acids (Perez $\&$ Briz, 2009). Despite its low abundance it has been shown to have direct antioxidant properties especially against hydroxyl radicals and can also prevent the retention of certain toxic hydrophobic bile acids. UDCA has also a number of therapeutic applications including dissolving gall stones and as an alternative therapy for hepatitis $\mathrm{C}$ patients in place of interferon therapy (Arisawa et al, 2009; Lapenna et al, 2002). This particular bile acid has also shown promise as a potential targeted therapy for colorectal cancer (Debruyne et al, 2001).

This study aims to demonstrate if biofluid components can mediate nanoparticle toxicity. Their incorporation may enhance or reduce cytological effects and has often been overlooked in cytotoxicity screening, which will be addressed here. The European Union define a nanomaterial as "A natural, incidental or manufactured material containing particles in an unbound state or as an aggregate or as an agglomerate, and where for $50 \%$ or more of the particles in the number size distribution, one or more external dimensions is in the range 1-100nm" (European Commission, 2011). In keeping with this definition it is important to investigate the interaction of biofluid components with nanoparticles to determine if the chemistry is affected resulting in a change in size distribution or agglomerative state potential causing the nanoparticles to fall outside the criteria of a nanomaterial as per the EU definition. The effect of biofluid components on the size distribution and agglomerative state of AgNP was investigated using dynamic light scattering analysis and zeta potential analysis. The cell lines chosen were HepG-2 a hepatocellular carcinoma (liver) and Hep2 an epithelial cell line employed as a control. A cytotoxic profile of AgNP was carried out using the standard cytotoxic assays 3-(4, 5-Dimethylthiazol-2-yl)-2, 5diphenyltetrazolium bromide (MTT) and Alamar Blue (AB) viability assays. A 2', 7'dichlorofluorescin diacetate (DCFH-DA) plate assay was used to detect any intracellular ROS generations in response to AgNP exposure.

\section{Materials and Methods}

\section{Test materials and reagents}

Polyvinylpyrrolidone (PVP) coated silver (Ag) nanopowder of < 100nm Catalogue No: 758329, was purchased from Sigma-Aldrich Ltd (Dublin, Ireland). PVP coating was confirmed by XRD analysis. 3-(4,5-Dimethylthiazol-2-yl)-2,5-diphenyltetrazolium bromide (MTT) Catalogue No: M5655 and 2',7'- dichlorofluorescin diacetate (DCFH-DA) Catalogue No: D6883 as well as cell culture media, supplements and trypsinisation solution were all purchased form Sigma-Aldrich 
Ltd (Dublin, Ireland). Alamar blue (AB) was purchased from Biosciences (Dublin, Ireland). UDCA, CA and DCA were purchased from Sigma-Aldrich (Dublin, Ireland).

\section{Cell culture}

HepG-2 cells (ATCC: HB-8065) an immortalized hepatocellular carcinoma cell line and Hep2 (ATCC: CCL-23) a cell line of laryngeal origin were employed in this study. HepG-2 cells were cultured in Dulbecco's Modified Eagle's Medium (DMEM) with 2mM L-glutamine, sodium pyruvate and supplemented with $10 \%$ foetal bovine serum (FBS) at $37^{\circ} \mathrm{C}$ in humidified $5 \% \mathrm{CO}_{2}$. Hep2 cells were cultured in RPMI-1640 medium supplemented with 10\% FBS, 45 IU/ml penicillin and $45 \mathrm{IU} / \mathrm{ml}$ streptomycin at $37^{\circ} \mathrm{C}$ in humidified $5 \% \mathrm{CO}_{2}$. All cell culture media including FBS other reagents and supplements are from Gibco purchased through Biosciences (Dublin, Ireland).

\section{Characterization of nanoparticles}

Prior to the cytotoxicity testing, pristine AgNP and AgNP in various dispersions in the presence of each biofluid component were characterized. The suspensions of AgNP were prepared in deionised water $\left(\mathrm{dH}_{2} \mathrm{O}\right)$, DMEM and RPMI media using a bath-sonicator for 20 minutes (DegussaNey ULTRAsonik 57X 50/60 Hz, California, USA) prior to size and zeta potential analysis. Dynamic light scattering and zeta potential measurements were performed with the aid of a Malvern ZetaSizer Nano ZS (Malvern Instruments, Worcestershire, UK) operating with version 5.10 of the systems Dispersion Technology Software (DTS Nano). For size measurement DTS0012 disposable sizing cuvettes were used. The samples were equilibrated at $25^{\circ} \mathrm{C}$ for 2 minutes before each measurement. For zeta potential analysis, DTS1060T clear disposable zeta cells were used and measurements were performed with the automatic model setting, using a voltage of five to minimize artefacts and charring of media proteins during analysis.

Scanning Electron Microscopy (SEM) was also employed to estimate nanoparticle size from the images produced by this technique. A Hitachi SU 6600 FESEM instrument was used to obtain images of the AgNps. First the SEM was calibrated with Au on Carbon standard provided by Agar Scientific (Essex, UK). Samples were prepared by dispersing particles in ethanol by sonication 750 watts Ultrasonic Processor tip (Branson Ultrasonics, Ultra sonic processor VCX-750W) at $40 \%$ amplitude for a total of 45 seconds. Samples were spin coated onto pure silicon wafer which had been thoroughly cleaned by sonication in acetone for 30 minutes followed by boiling in propanol for 30 minutes. Silicon wafers were then left to air dry in a dust free environment and the nanoparticle sample was then spin coated onto wafers 24 hours prior to measurement.

The specific surface area of AgNP was established with a Micrometrics GEMINI BET. BET sample holders were filled with a known mass of powdered nanoparticles and measured. The sample was degassed for two hours at room temperature with nitrogen gas prior to analysis. Nitrogen gas was used as the absorptive gas and a multipoint method was used in the estimation of specific surface area.

\section{Cytotoxic evaluation}


The AB and MTT assays were performed for assessment of cytotoxicity of AgNP to the three cell lines. The test used a range of eight concentrations of AgNP $(3.91-500 \mu \mathrm{g} / \mathrm{ml})$ in which effects were likely to occur, this in turn allowed inhibitory concentration $\left(\mathrm{IC}_{50}\right)$ to be calculated. In all cases results were compared to an unexposed control (cells in culture media only), eliminating any dependence of the cell line exposures on well type, seeding efficiency and numbers, exposure times and volumes. A stock suspension of AgNP was prepared aseptically from which different concentrations of nanoparticles were prepared in the respective HepG-2 and Hep2 cell media followed by sonication (Branson Ultrasonics, Ultra sonic processor VCX-750W, maximum amplification 40\%). As a positive control 10\% DMSO was prepared in the respective media. For cytotoxic analysis of nanoparticles in the presence of biofluid components, a range finding experiment was performed to determine concentration of interest for the definitive experiment. A stock solution of this test concentration was prepared for each biofluid component, UDCA, CA and DCA, in the appropriate cell media. A dose finding experiment for each bile acid was performed in the respective cell lines to determine a working concentration for cytotoxic studies. The working concentration was noted to have no cytotoxic effect when exposed to cells alone. Based on the dose finding experiments and previous studies concentrations of $50 \mu \mathrm{M}, 1 \mathrm{mM}$ and $0.125 \mathrm{mM}$ were prepared for UDCA, CA and DCA respectively and a concentration of $2.2 \times 10^{-}$ ${ }^{7}$ M UDCA was prepared for Hep2 cell line (Arisawa et al, 2009). Using this solution of each biofluid component, a stock dispersion of AgNP was prepared aseptically from which a range of nanoparticle concentrations was prepared. For all assays and exposure scenarios fresh nanoparticle suspensions were prepared for each experiment.

\section{Alamar Blue assay}

For the AB assay, cells were seeded in 96 well microtitre plates (Nunc, Denmark) at a density of $1 \times 10^{5}, 5 \times 10^{4}, 4 \times 10^{4}$ and $3 \times 10^{4}$ cells $/ \mathrm{ml}$ for $24,48,72$ and 96 hour exposures respectively in $100 \mu 1$ of cell culture media containing $10 \%$ FBS. At least three independent experiments were conducted with six replicate wells employed per concentration per plate in each independent experiment. After 24 hours of cell attachment, plates were washed with $100 \mu 1 /$ well PBS and treated with increasing concentrations of AgNP prepared in media for 24, 48, 72 and 96 hours. All incubations were performed at $37^{\circ} \mathrm{C}$ in a $5 \% \mathrm{CO}_{2}$ humidified incubator. The assay was performed according to manufacturer's instructions. Briefly, control media and test exposures were removed, cells were rinsed with $100 \mu \mathrm{l}$ PBS and $100 \mu \mathrm{l}$ of AB solution (5\% [v/v] solution of AB) prepared in fresh media with no added supplements were added to each well. After 3 hour incubation $A B$ fluorescence was measured at excitation and emission wavelength of $531 \mathrm{~nm}$ and $595 \mathrm{~nm}$ respectively in TECAN GENios (Grodig, Austria). Wells containing AB solution and media only were used as blanks. For this assay the mean fluorescence units for six replicate cultures were calculated for each exposure treatment. Acellular studies were performed with test particles and the $\mathrm{AB}$ dye to confirm no interference of the particle with dye conversion (Gupta Mukherjee et al, 2012).

\section{MTT assay}


As with the AB assay a parallel set of three plates were set up for the MTT assay, seeded and exposed as previously described. After the same exposure times as AB assay, 24, 48, 72 and 96 hours, test medium was removed. Cells were washed with $100 \mu \mathrm{l}$ PBS and $100 \mu \mathrm{l}$ of freshly prepared MTT solution (5mg/ml MTT in media \{without supplements ) was added to each well.

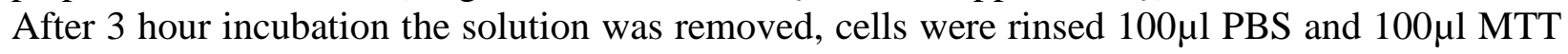
fixative (DMSO) was added to each well. Plates were shaken at 240rpm for 10 minutes. Following this step the supernatant was removed and transferred to a new 96 well plate for analysis as it has been observed that sedimentation of AgNP on the bottom of wells interferes with absorbance readings producing higher values. Absorbance was read at 595nm in TECAN GENios (Grodig, Austria). Acellular studies were performed with test particles and the $\mathrm{AB}$ dye to confirm no interference of the particle with dye reduction (Gupta Mukherjee et al, 2012).

\section{Reactive Oxygen Species (ROS) studies}

Intracellular oxidative stress was quantified using a 2', 7'-dichlorofluorescin diacetate (DCFHDA) plate assay to detect intracellular hydroperoxides and probe for a wide range of ROS. Confluent cells were trypsinized and seeded at a density of $1 \times 10^{5}$ cells $/ \mathrm{ml}$ prepared in media, onto 96 well black bottomed plates (Nunc, Denmark) and allowed to attach for 24 hours. Six independent experiments were performed with six replicate wells for negative control, positive control and test concentrations on each plate. A working stock of $20 \mu \mathrm{M}$ DCFH-DA in PBS was prepared and all test concentrations, positive and unexposed negative controls were prepared in this working stock and exposed to cells. The negative control consisted of $20 \mu \mathrm{M}$ DCFH-DA in PBS only, the positive control was $5 \mu \mathrm{M}$ hydrogen peroxide $\left(\mathrm{H}_{2} \mathrm{O}_{2}\right)$ prepared in DCFH-DA/PBS working stock and the AgNP test concentrations $(3.91-500 \mu \mathrm{g} / \mathrm{ml})$ together with the AgNP-biofluid component test concentrations were prepared in the DCFH-DA/PBS working stock. Prior to cellular testing, acellular studies were performed with the test particles and the DCF dye at all test scenarios to confirm no reduction of the dye due to AgNP interference. No reduction of DCFHDA by AgNP was noted (Gupta Mukherjee et al, 2012).

After 24 hours of attachment, the media was removed and wells were washed with PBS, $100 \mu \mathrm{l} /$ well. Cells were then treated with $100 \mu \mathrm{l}$ of positive control, negative control and test concentrations and plates are incubated for $15 \mathrm{~min}, 30 \mathrm{~min}, 1 \mathrm{hr}, 2 \mathrm{hr}, 3 \mathrm{hr}, 4 \mathrm{hr}, 5 \mathrm{hr}$ and $6 \mathrm{hr}$. The rate of intracellular ROS production was monitored at each time point by the emission of DCFH-DA at $529 \mathrm{~nm}$ by excitation at $504 \mathrm{~nm}$ at the various time points (plates were re-incubated after each time point reading). Readings were performed on a TECAN GENios plate reader (Grodig, Austria).

\section{Confocal Microscopy}

Confluent cells were trypsinized and at a concentration of $1 \times 10^{5}$ cells $/ \mathrm{ml}, 100 \mu \mathrm{l}$ of cell suspension were seeded onto 35mm glass bottom dishes (MatTek Corporation, Ashland, MA, USA). Glass dishes were incubated for 1 hour. Following incubation $1 \mathrm{ml}$ of cell culture media was added to cell suspensions. Dishes were re-incubated and allowed to attach for 24 hours. A working stock of $10 \mu \mathrm{M}$ CM-H ${ }_{2}$ DCFDA (Molecular Probes- Invitrogen, California, USA) was prepared in DMSO. 
A stock suspension of AgNP was prepared aseptically from which different concentrations of nanoparticles were prepared in cell media followed by bath-sonication (Degussa-Ney ULTRAsonik 57X, California, USA). As a positive control, 10\% DMSO was prepared in the respective media. The negative control consisted of cell culture media only.

After 24 hours of attachment, media was removed and glass dishes were washed with PBS $1 \mathrm{ml} /$ dish. Cells were treated with $100 \mu \mathrm{l}$ of $\mathrm{CM}-\mathrm{H}_{2}$ DCFDA and incubated for 30 minutes. After incubation, dishes were washed in PBS $1 \mathrm{ml} /$ dish. $1 \mathrm{ml}$ test concentrations, negative and positive controls were added to dishes and incubated for 1 hour. After incubation dishes were washed in PBS $1 \mathrm{ml} /$ dish and imaged immediately. Images were taken on a Zeiss 510 LSM confocal microscope with an external argon ion laser source of $488 \mathrm{~nm}$ excitation and using a bandpass filter of 505-530nm to detect the fluorescent DCF dye.

\section{Statistical analysis}

At least three independent experiments were performed for each cytotoxicity endpoint. Results for each assay were expressed as a percentage of unexposed control \pm standard deviation with control values set as $100 \%$. Statistically significant differences between samples and their respective controls were calculated using the statistical analysis package InStat. Statistically significant differences were set at $\mathrm{p}<0.05$. Normality of data was confirmed with Q-Q percentile plots and Kolmogorov-Smirnov tests. Equality of variances was evaluated using Levène tests. One-way analysis of variances (ANOVA) followed by Dunnett's multiple comparison tests were carried out for normally distributed samples with homogeneous variances. Non-parametric tests, namely Kruskal-Wallis followed by Mann-Whitney-u-tests were applied to samples without normal distribution and/or inhomogeneous variances. Cytotoxicity data (where appropriate) was fitted to a sigmoidal curve and a four parameter logistic model used to calculate the Inhibitory Concentration $\left(\mathrm{IC}_{50}\right)$ values. The $\mathrm{IC}_{50}$ value refers to a concentration of a compound where a $50 \%$ effect is observed in this case a reduction in cell viability. $\mathrm{IC}_{50}$ values were reported as $\pm 95 \%$ confidence intervals. $\mathrm{IC}_{50}$ values were estimated using XLfit3 ${ }^{\mathrm{TM}}$, a curve fitting add on for Microsoft ${ }^{\circledR}$ Excel (ID Business Solutions, UK).

\section{Results}

\section{Particle characterization}

The methods of particle characterization employed to determine the relative size of $\mathrm{AgNP}$ as purchased and in various suspensions were Scanning Electron Microscopy and Dynamic Light Scattering. Figure 1 shows SEM analysis of a dilute sample of AgNP. This sizing method was performed on pristine particles as purchased from Sigma-Aldrich (Catalogue No: 758329). In order to obtain an accurate size reading a sample number of particles (eg. 100 particles) were chosen and their average size determined. SEM revealed spherical particles with an average particle size of $30 \mathrm{~nm}$. This method reflects the physical particle diameter of the pristine particles as purchased. In a study published by Gupta Mukherjee et al (2012) SEM analysis determined a diameter of <50nm 
for the same Sigma-Aldrich AgNP employing the same preparation method for SEM analysis as this study (Gupta Mukherjee et al, 2012). While this method of particle sizing provides useful information on the pristine AgNP, it does not represent how particles will be presented to biological systems upon entering the body and how the various biofluids they come into contact with may affect them. While SEM analysis provides a fast analysis of nanoparticles with a simple sample preparation, analysis of biological samples by this method requires fixation and any change in nanoparticle size due to interaction with biological material cannot be monitored by this method. DLS analysis will allow monitoring of the system AgNP are suspended in and provide data on particle hydrodynamic radius and any change that occurs due to the presence of certain biological material, in this case protein components of cell culture media and biofluid components.

DLS size measurements were performed on pristine AgNP suspended in $\mathrm{dH}_{2} \mathrm{O}$ and cell culture media with and without the addition of the tested biofluid components to the media. Three concentrations of AgNP were chosen for DLS analysis the highest concentration in which particles were dispersed, $62.5 \mu \mathrm{g} / \mathrm{ml}$, a low concentration where particles were still visible when dispersed, $3.9 \mu \mathrm{g} / \mathrm{ml}$ and a concentration in between $15.6 \mu \mathrm{g} / \mathrm{ml}$. DLS data from this study is illustrated in figure 2 (a)-(d). When suspended in a biological media the various proteins within that media can associate with any nanoparticles present and it is postulated that this protein coating can determine the response of biological systems rather than the particles themselves (Lynch et al, 2007). It can be assumed that any protein association that occurs in the nanoparticle dispersions presented here may impact the hydrodynamic radius of particles and cause possible agglomeration.

The concentration of $15.6 \mu \mathrm{g} / \mathrm{ml}$ was chosen as a representative concentration between a high and low concentration of $\mathrm{AgNP}$, it is also a concentration at which an effect on cells is observed as will be discussed later. From DLS analysis, particle size in $\mathrm{dH}_{2} \mathrm{O}$ was determined to be $34 \mathrm{~nm} \pm \mathrm{SD}$ $3.5 \mathrm{~nm}$. A shift in hydrodynamic radius was observed in preparations of AgNP in RPMI. Dispersed in RPMI alone there are two clear peaks observed one representing RPMI itself and the other at approximately 40nm representing AgNP. Upon addition of UDCA to the dispersion it does not appear to have an effect on the hydrodynamic radius. The two peaks are still observed with only a slight increase in size distribution. This variation may be explained by a shift in the plane of shear upon addition of UDCA as UV-Vis spectroscopic analysis demonstrated no significant interaction of AgNP with the cell culture media components. In the presence of DMEM there is shift in the distribution of $\mathrm{AgNP}$ compared to their dispersion in $\mathrm{dH}_{2} \mathrm{O}$. The first peak remains relatively unchanged apart from a reduced number of particles falling within this size range. The second wider peak demonstrates the greatest change with the majority of particles falling within this size range which has shifted to below 100nm. However upon addition of UDCA, CA and DCA (figure (b) - (d)) significant changes are noted with only one peak between 1-10nm observed which was attributed to DMEM. Ursodeoxycholic acid, cholic acid and deoxycholic acid have a large size distribution (greater than 200nm) and may result in the formation of large agglomerates with nanoparticles, causing them to precipitate out at an elevated rate preventing their detection by DLS analysis resulting in the detection of DMEM only. Further investigation is required into why these particular dispersions of AgNP and biofluid components cannot be detected by DLS analysis and how this will ultimately affect their toxicological testing. 
The UV-Vis absorption analysis of the different preparations of AgNP and cell culture media demonstrated no significant changes to the spectra. No alterations in spectra were noted suggesting that secondary toxicity caused by nutrient depletion would be unlikely.

Zeta potential analysis, illustrated in Table 1, was performed using the same sample preparations as for sizing analysis. Typically values above $30 \mathrm{mV}$ or below $-30 \mathrm{mV}$ indicate stability of the overall system. Zeta potential analysis of AgNP dispersed in $\mathrm{dH}_{2} \mathrm{O}$ showed instability of particles at all test concentrations which is unexpected as the particles purchased are PVP coated. When the particles were dispersed in the test media differences were noted and the AgNP in RPMI demonstrated stable results, whereas interestingly dispersion of AgNP in DMEM was revealed to be unstable. Upon the addition of the bile components CA, DCA and UDCA however the system was also found to be unstable. The large values noted when particles are dispersed in media and media with biofluid components would suggest a tendency to repel each other and as such reduce the likelihood of agglomeration (Xia et al, 2006). It can be assumed from the data that the addition of biofluid components does not modify the overall stability of the system.

BET analysis was also employed to determine surface area of pristine powder and yielded a surface area of $2.3 \pm 0.1 \mathrm{~m}^{2} / \mathrm{g}$.

\section{Cytotoxicity Testing}

Viability assays were performed to determine the effect of AgNP exposure to HepG-2 and Hep2 cell lines. The ability of the biofluid components UDCA, CA and DCA to modify the toxic response of AgNP was also evaluated. Cytotoxicity data for AgNP exposure in the HepG-2 and Hep2 cell lines are presented in table 2. The results of the MTT assay are presented for each cell line in the presence and absence of the respective biofluid component. Both MTT and AB assays were performed for each cell line. Results for $\mathrm{AB}$ assay are not shown.

\section{Cytotoxic evaluation HepG-2 cell line to AgNP exposure alone and in the presence of UDCA, CA and DCA}

Figure 3 represents the cytotoxic response of HepG-2 cells to AgNP exposure determined by the MTT assay. In the presence of AgNP cell viability decreases in a dose and time dependent manner, with a substantial decline in mitochondrial integrity detected at concentrations of $15.6 \mu \mathrm{g} / \mathrm{ml}$ and above. A significant decrease in cell survival occurs at concentrations of $15.6 \mu \mathrm{g} / \mathrm{ml}$ after 48 hour exposure while a significant reduction in cell viability at all exposure time points occurs at AgNP concentrations of $31.25 \mu \mathrm{g} / \mathrm{ml}$ and upwards.

A DCF-DA plate assay was employed to detect any ROS production in response to AgNP exposure over a 24 hour period. Readings were taken every hour for 6 hours. Following this

readings were then taken at 12 and 24 hours to detect any delayed intracellular ROS production in response to increasing concentrations of nanoparticle exposure. Figure 4 illustrates ROS generation in response to AgNP exposure. The study shows that the amount of ROS produced 
increases with increasing length of nanoparticle exposure and also with increasing concentration. ROS production was noted at concentrations of $7.8 \mu \mathrm{g} / \mathrm{ml}$ and above after 15 minutes exposure and was seen to increase with dose and exposure time. The greatest level of ROS production was observed at a concentration of $500 \mu \mathrm{g} / \mathrm{ml}$ after 12 hours of exposure. A reading at 24 hours shows a decline in ROS production compared to the 12 hour time point which can be associated with cell death. Confocal microscopy was employed to confirm ROS induction due to AgNP exposure at a concentration of $31.25 \mu \mathrm{g} / \mathrm{ml}$ in figure 5 .

Figures 6 and 7 show the toxic response of AgNP to HepG-2 cells, but in the presence of UDCA. The same dose dependent response was noted as with the previous assays, following exposure to AgNP alone with this response increasing over time. The MTT assay (figure 6) showed a significant decline in cell viability after 96 hours at a concentration of $7.81 \mu \mathrm{g} / \mathrm{ml}$. At a $15.6 \mu \mathrm{g} / \mathrm{ml}$ concentration of AgNP a significant decrease in viability is observed following 48, 72 and 96 hour exposures. It was only at concentrations of $31.25 \mu \mathrm{g} / \mathrm{ml}$ and above that a significant reduction in cell survival is seen at all exposure time points. Interestingly the presence of UDCA appears to have had no effect on cellular response to AgNP exposure, with almost identical patterns of toxicity observed both with and without the addition of UDCA. This suggests that the presence of UDCA does not modify AgNP toxicity.

In the presence of UDCA (figure 7) a similar pattern of ROS production was observed as with the AgNP exposure alone although it appears more erratic with larger error bars. The same dose and time dependent response was observed with ROS induction detected following 15 minute exposure at concentrations as low as $3.91 \mu \mathrm{g} / \mathrm{ml}$. A similar trend was observed with ROS induction in the presence of $\mathrm{AgNP}$ alone and a maximum ROS production was observed at a concentration of $500 \mu \mathrm{g} / \mathrm{ml}$ after 12 hour exposure. Following 24 hour exposure ROS production was seen to decline, again this can be attributed to cell death. ROS induction by a concentration of $31.25 \mu \mathrm{g} / \mathrm{ml}$ AgNP was confirmed by confocal microscopy illustrated in figure 8. It is apparent from the data that UDCA does not alter oxidative stress induced by AgNP exposure and it can be concluded that UDCA does not mediate AgNp ability to induce intracellular ROS production.

Figure 9 represents the exposure of HepG-2 cells to AgNP in the presence of cholic acid (CA). Again a dose and time dependent response to AgNP exposure was observed with this assay. A noted decline in cell viability can be seen after 24 hours of exposure at an AgNP concentration of $3.91 \mu \mathrm{g} / \mathrm{ml}$ and then an apparent increase in viability compared to the unexposed control after longer exposure periods at the same concentration, indicative of a possible cell recovery. At an AgNP concentration of $3.91 \mu \mathrm{g} / \mathrm{ml}$ after a 24 hour exposure a significant decline in cell viability is apparent. At exposure times of 48 and 72 hours a significant decline in viability was also observed when compared to the unexposed control. At $15.6 \mu \mathrm{g} / \mathrm{ml}$ and above significant reduction in cell survival could be seen at all exposure concentrations when compared to the unexposed negative control. As observed with UDCA, the addition of CA does not appear to modify the toxicity of $\mathrm{AgNP}$ and the response in the presence of CA is seemingly identical, with no significant difference or change between the two. 
Further studies were performed with the DCF-DA plate assay to determine the ability of AgNP with addition of CA to induce oxidative stress. Figure 10 demonstrates ROS production in a dose and time dependent manner. Generation of ROS is seen at the higher concentrations of AgNP 125, 250 and $500 \mu \mathrm{g} / \mathrm{ml}$. Induction of intracellular ROS was noted after 15 minutes of exposure compared to the unexposed control with the highest generation detected after this time and at the highest AgNP concentration $500 \mu \mathrm{g} / \mathrm{ml}$. After 15 minutes of exposure ROS production begins to decline in a step-wise pattern as exposure time progresses with no ROS detected after the 4 hour exposure point. In comparison to HepG-2 exposure to AgNP alone, the addition of CA alters the pattern of ROS production. In the presence of CA, ROS induction occurs almost immediately after exposure to AgNP and then declines rapidly compared to earlier time points with no ROS detected after 4 hours. Induction of ROS only occurs at the higher exposure concentrations 125, 250 and $500 \mu \mathrm{g} / \mathrm{ml}$. Exposure to AgNP alone results in a much lower percentage of ROS induction compared to the unexposed control that increases over time and only begins to decline after 12 hours of exposure. In the presence of CA induction of ROS occurs much quicker but declines at a similar rate whereas in the presence of AgNP only ROS production is more sustained over time. Conformation of ROS induction by AgNP at a concentration of $3.91 \mu \mathrm{g} / \mathrm{ml}$ in the presence of $1 \mathrm{mM}$ CA was verified by confocal microscopy as illustrated in figure 11 .

Figure 12 illustrates the toxic response of HepG-2 cells to AgNP exposure in the presence of deoxycholic acid (DCA). As can be seen in figure 9 a loss in mitochondrial integrity is demonstrated at the lowest AgNP concentration of $3.91 \mu \mathrm{g} / \mathrm{ml}$ at all exposure time points. Significant loss is seen at a concentration $3.91 \mu \mathrm{g} / \mathrm{ml}$ after 24 hour exposure. There is significant reduction at this concentration after 72 and 96 hour incubations but not after 48 hour incubation again this may be due to cell recovery. As the AgNP are in low doses it is possible they have fallen out of solution at this time and any effect was induced within the first 6-12 hours following exposure. After this point any surviving cells may be starting to recover and replicate. The same pattern is observed at a concentration of $7.81 \mu \mathrm{g} / \mathrm{ml}$. A significant reduction is observed at all exposure time points from a concentration of $15.6 \mu \mathrm{g} / \mathrm{ml}$ and above.

The induction of ROS upon exposure to AgNP with the addition of DCA (figure 13) follows a similar pattern to that observed with the addition of CA. However it can be seen that ROS are induced at much lower concentrations of $\mathrm{AgNP}$ when compared to the $\mathrm{CA}$ and in the presence of AgNP alone. ROS were detected after 15 minutes at a concentration of $31.25 \mu \mathrm{g} / \mathrm{ml}$ and higher with maximum ROS production occurring at $500 \mu \mathrm{g} / \mathrm{ml}$ after a 15 minute exposure. After 15 minutes ROS levels begin to decline with increasing exposure time. When compared to exposure of HepG-2 cell to AgNP alone the observed ROS induction occurs at lower concentrations of AgNP and does not increase with time but begins to decline after 15 minutes. Indeed to the case of CA, where ROS induction occurs much earlier but is short lived. It appears that AgNP exposure in the presence of DCA results in the greatest ROS induction compared to the unexposed control and at lower doses when compared to the AgNP exposure with CA and AgNP exposure alone. Confirmation of ROS induction by $\mathrm{AgNP}$ at a concentration of $3.91 \mu \mathrm{g} / \mathrm{ml}$ in the presence of $0.125 \mathrm{mM}$ DCA is confirmed by confocal microscopy as illustrated in figure 14 . 
The AB assay was also performed for the HepG-2 cell line in the presence and absence of UDCA, $\mathrm{CA}$ and DCA where a dose and time dependent response was also observed resulting from AgNP exposure. $\mathrm{AB}$ gives a more general picture of the loss in cell viability by targeting the cytosol of the cell and detecting a change in the cytosolic environment. A similar pattern of toxicity was observed with the addition of DCA having a substantial effect on cell viability occurring after 24 hours of exposure (data not shown).

Statistical analysis $(\mathrm{p}<0.05)$ comparing the differences in toxicity induced by AgNP alone and in the presence of the tested biofluid components highlighted statistically significant differences between the toxicological data. The presence of CA and DCA significantly altered the cytotoxic effect induced by AgNP on HepG-2 cells at a concentration of $15.6 \mu \mathrm{g} / \mathrm{ml}$ and above the response curves were found to be statistically $(\mathrm{p}<0.05)$ different. This change was noted at 48,72 and 96 hour time points. UDCA was noted not to significantly alter the toxicity of AgNP in HepG-2 cells.

\section{Cytotoxic evaluation of Hep2 cell line to AgNP exposure alone and in the presence of UDCA}

As a control, another cell line was tested to establish if biofluid components could modify the effects of AgNP exposure in areas other than their target organs. To investigate this, the Hep2 cell line was selected. The same exposure concentrations were employed and the effects of AgNP toxicity in the presence of biofluid components were investigated. UDCA was chosen as the test bile acid. A dose finding experiment was performed to determine the highest concentration of UDCA that the Hep2 cell line could withstand without causing toxicity. This concentration was found to be $2.2 \times 10^{-7} \mathrm{M}$ and this is the working concentration that was employed for the following experiments.

Figure 15 displays the cytotoxic response of Hep2 cells to AgNP exposure determined by the MTT assay. This assay demonstrates a typical dose and time dependent pattern with significant reduction in cell survival is seen at all concentrations following 72 hour exposure. A significant reduction in viability after 72 and 96 hours was observed at doses of $7.81 \mu \mathrm{g} / \mathrm{ml}$ and above and after 48 hours at a concentration of $31.25 \mu \mathrm{g} / \mathrm{ml}$ and above. Furthermore a significant decrease in cell survival compared to the unexposed control was observed for all exposure time points at a concentration of $62.5 \mu \mathrm{g} / \mathrm{ml}$ and above.

Figure 16 illustrates the toxic response of AgNP to Hep2 cells in the presence of UDCA. The data demonstrate that in the presence of UDCA there is a dramatic reduction in cell viability compared to when cells are exposed to AgNP alone. No significant change in cell viability occurs after 24 hour exposure but a significant reduction following 48, 72 and 96 hour exposures was noted at all tested concentrations of AgNP. The data presented illustrates that compared to AgNP exposure alone the presence of UDCA does mediate toxicity. 
A DCF-DA plate assay was also employed to investigate intracellular oxidative stress, to see if the presence of UDCA could influence the generation of ROS in response to AgNP exposure. Exposure to increasing concentrations of AgNP induced ROS production in a dose and time dependent manner (figure 17). ROS production was detected at exposure concentrations of $7.81 \mu \mathrm{g} / \mathrm{ml}$ and above with maximum production seen at $500 \mu \mathrm{g} / \mathrm{ml}$. Induction of ROS was observed after 15 minutes of exposure with maximum production observed after 1 hour after which levels of detectable ROS began to decline. In the presence of UDCA (figure 18) a substantial reduction in ROS generation was observed when compared to exposure to AgNP alone and ROS were only detected at higher concentrations of AgNP above $250 \mu \mathrm{g} / \mathrm{ml}$. A maximum level ROS production with added UDCA was observed at a concentration of $500 \mu \mathrm{g} / \mathrm{ml}$ after 1 hour and as illustrated by the data the percentage of ROS induction when compared to the negative control is substantially reduced compared to the amount generated in the absence of UDCA.

The AB assay was also performed for the Hep2 cell line in the presence and absence of UDCA where a dose and time dependant response was also observed resulting from AgNP exposure. A similar pattern of toxicity was observed with the addition of UDCA having a substantial effect on cell viability occurring after 24 hours of exposure (data not shown).

Statistical analysis $(\mathrm{p}<0.05)$ comparing the differences in toxicity induced by AgNP alone and in the presence of UDCA in Hep2 cells highlighted statistically significant differences between the toxicological data. A significant effect on toxicity was noted in the presence of UDCA from the lowest test concentration up to $250 \mu \mathrm{g} / \mathrm{ml}$ after 48 and 96 hour time points compared with exposure to AgNP alone.

\section{Discussion}

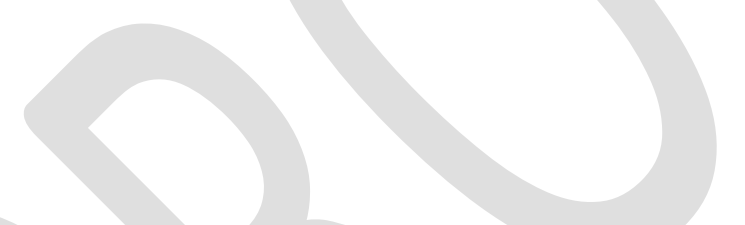

It is clear from the literature that exposure to nanoparticles is becoming more widespread mainly due to their continued incorporation into various consumer products. Upon exposure, nanoparticle contact with surfactants and biofluids is inevitable and it is important to take these events into account when examining toxicity. This study aimed to investigate this interaction to identify a possible modification of toxicity by individual components of one of the major biofluids within the body.

The physiochemical characteristics of AgNP play an important role in how they will interact with biological systems. The size, associated surface area, shape and chemical composition have all been shown to be of great importance to nanoparticle toxicity. Size influences surface area which leads to greater cell contact, while truncated triangular nanoparticles show increased toxicity compared to spherical nanoparticles and it is believed that cylindrical particles can cross the cell membrane easier than other shapes due to their ability to harness the clatherin machinery (Renwick et al, 2004; Rai et al, 2009; Kam et al, 2004).

It is now well established that upon entry into the body nanoparticles almost immediately become coated in protein and that this adsorbed layer or "corona" is important in biological responses to nanoparticle exposure (Gray, 2004; Lynch \& Dawson, 2008). While there will be adsorption of the proteins of biofluid components and cell culture media onto the nanoparticle surface, it can be 
assumed that these proteins will associate and dissociate from AgNP at different rates depending on a factors such as concentration and affinity (Lynch et al, 2007).

Proteins tend to agglomerate upon dispersion in an aqueous solution and may coat AgNP trapping them within agglomerates increasing the rate at which they fall out of solution. A number of studies have investigated this dispersion to determine how this affects overall toxicity. It is known that nanoparticles once suspended in cell culture media can precipitate out of solution and agglomerate at different rates. As such this raises a number of questions relating to dosimetry and the effect of agglomerate formation on the end result of nanoparticle exposure. As well as influencing the results of toxicity it can also influence exposure times as agglomerate formation and precipitation may increase the time taken for delivery of the full dose to cells. Further investigation is required to develop a method of including dosimetric parameters into toxicological testing so that accurate results for in vitro assays can be obtained that are comparable to animal models (Cohen et al, 2014; Cohen et al, 2013; Kroll et al, 2009; Teeguarden et al, 2007).

Zeta potential analysis was also performed and a change in values would indicate interaction of nanoparticles with biofluid components and cell culture media, suggesting indirect toxicity caused by their interaction (Casey et al, 2007; Casey et al, 2008). No change on overall stability was noted following biofluid component addition. The overall particle stability also influences size and agglomerative state. Larger unstable zeta potential values were noted for AgNP dispersions in media with biofluid component addition. These large values suggest particles will repel each other reducing the potential to agglomerate. The dispersant plays a role in particle stability thus effecting size and possible agglomeration (Xia et al, 2006).

A recent study demonstrated that AgNP exposed to synthetic stomach fluid led to transformations in the particles including particle aggregation, changes in particle morphology and the release of silver ions (Mwilu et al, 2013). It was suggested that alterations to AgNP size and surface properties due to exposure to synthetic stomach acid may impact on their transformation through the gastrointestinal tract and may in turn influence AgNP interaction with the cells they encounter. The binding of proteins be it from cell culture media or biofluid components can aid in the binding of particles to cell surfaces, their trafficking through biological systems and the resulting effects will also be altered. Very recently in a study by Wang et al (2013), the protein surface coating or "corona" was identified as providing a Trojan horse effect to nanoparticles. Initial entry of nanoparticles into the cell did not cause immediate toxicity, it was only when the nanoparticles were transported to the lysosome and the corona was degraded in the acidic environment that toxicity was observed. At this point, much later after initial exposure, loss of lysosomal integrity and release of its contents was observed followed by cell death via apoptosis (Wang et al, 2013). These findings can be related to the work undertaken in this study as biofluid components are protein entities and will ultimately form part of the protein corona and may contribute to particle interactions with living systems and any related toxicity.

This reiterates the importance of performing realistic exposure scenarios in toxicological testing to determine nanoparticles interactions in biological systems. These results highlight the importance of establishing the physiochemical characteristics of AgNP in a variety of biological suspensions as their interactions with these components influence their interactions with cellular components and biological systems and will ultimately determine their distribution throughout the body and the signalling pathways and end responses they induce. 
The cytotoxicity studies undertaken illustrate that mitochondrial integrity (MTT) and the general health of the cell (AB) is affected by exposure to AgNP and that the chosen biofluid components have different modifying effects. Table 2 concisely illustrates $\mathrm{IC}_{50}$ values for both assays providing an overall synopsis of toxicity. From the data presented it can be suggested CA and DCA do have some modifying effects. While not altering the pattern of toxicity in the viability assays, the pattern of ROS induction is altered upon their addition. The addition of CA and DCA induces greater levels of ROS induction with DCA producing the greatest response following a 15 minute exposure at the highest concentration of AgNP compared to the unexposed control. AgNP exposure alone produces much lower levels of ROS with maximum values only slight higher compared to the unexposed control. This increase in ROS production and at earlier points of exposure may suggest a more rapid or alternative pathway of cell death in the presence of CA and DCA. Previous studies have shown that lipid peroxidation by nanomaterials is a contributing factor to the generation of ROS and the overwhelming of natural antioxidant systems. ZnO is noted as enhancing lipid peroxidation contributing to increased ROS generation while AgNP exposure in rats can cause increased lipid peroxidation and quench naturally occurring antioxidants. It is postulated that the increased levels of ROS following AgNP-CA and AgNP-DCA exposure enhances lipid peroxidation within cells resulting in the greater levels of ROS noted compared to AgNP exposure alone (Premanathan et al, 2011; Adeyemi \& Faniyan, 2014). This upsurge in generation may be the result of a reactive product formed by the interaction of AgNP and biofluid components. Further investigation into the mechanism of cell death and the potential role of lipid peroxidation within cells must be investigated.

While no modification in toxicity by UDCA was noted in the HepG-2 cell line, modification was noted in Hep 2 cells. A delay in toxicity in the first 24 hours after exposure together with a reduction in ROS production strongly suggests that UDCA can modify Hep2 toxic response to AgNP exposure. While it appears to increase AgNP toxicity, ROS induction is significantly reduced suggestive of an antioxidant effect. This may indicate an alternative mechanism of cell death. These data indicate that UDCA can modify AgNP toxicity in a cell type different from that of its normal target.

While it is clear AgNP cause toxicity, it must be considered how much of this toxicity is attributed to the release of silver ions. A recent study by Beer et al (2012) addressed this phenomenon, identifying to what level the fraction of silver ions in various AgNP suspensions (commercially available and laboratory synthesized) influence toxicity (Beer et al, 2012). The study concluded that free silver ions in AgNP preparations do indeed play a considerable role in the overall toxicity of AgNP suspensions. However other studies are in agreement that at lower concentrations of metal ions, the uptake of nanoparticles leads to additional toxicity compared to higher concentrations where it appears the particles do not contribute to further toxicity (Navarro et al, 2008; Kim et al, 2009). Beer et al (2012) postulate that the mechanism of toxicity for AgNP is dissolution of particles in lysosomes, previously observed for copper oxide (CuONP) nanoparticles, possibly due to a protective barrier effect of the plasma membrane but this barrier can be evaded by a Trojan horse mechanism when nanoparticles are taken up by cells (Studer $e t$ al, 2010; Limbach et al, 2007). It must also be considered that sonication of AgNP suspensions and other preparation methods may have contributed to silver ion release and therefore toxicity. For example during sonication the energy released in order to break up large AgNP aggregates is converted to thermal energy which may promote dissolution of silver ions from particles (Liu \& 
Hurt, 2010). From this information it is clear that when investigating AgNP toxicity, the role of both silver ions and the particles themselves must be considered.

In order to monitor the potential mediation of the chosen biofluid components on AgNP toxicity in cells found outside of their normal target area, an epithelial laryngeal cell line was chosen. The biofluid components under study have been employed as pharmaceutical agents and medications. UDCA is widely used as a method of gallstone dissolution (Arisawa et al, 2009; Lapenna et al, 2002). This treatment has numerous trade names, including Actigall ${ }^{\mathrm{TM}}$ and BILIVER ${ }^{\mathrm{TM}}$, and is an oral treatment presented as an alternative to surgery. Cholic acid and deoxycholic acid also have medical applications. Cholic acid is used as treatment for children and adults with inborn errors in bile acid synthesis. Orphacol ${ }^{\mathrm{TM}}$ as it is known is taken orally and is vital in preventing the development of cholestatic liver disease (European Medicines Agency, 2013). Deoxycholic acid also has uses as a therapeutic drug used to treat localized fat deposits via subcutaneous injection. Studies have also reported the conjugation of heparin to deoxycholic acid in order to develop an oral delivery system for anticoagulant treatment preferable to the standard intravenous and subcutaneous injection (Lee et al, 2001; Kim \& Vaishali, 2006). The fact that these bile acids are or may be utilized in a medicinal capacity highlights that they will be present in areas of the body other than the liver. As such the data presented here on a laryngeal cell line is a relevant line of investigation given that in most cases these bile acid derived treatments are given orally. As the data demonstrate, the effect on toxicity in cell lines of different origins must be seriously considered and a more complete cytotoxic profile of AgNP to include exposure site contributions be established.

\section{Conclusion}

The data demonstrate that biofluid components can significantly influence the toxic profile of AgNP. As such future studies must consider the effects various biofluids and their components have on the processing of nanoparticles upon entry to the body, their presentation to cells, distribution and the biological processes they induce. Finally researchers must not just consider the toxicity of the isolated nanoparticles but that of a combined effect including, the local environment and the ions they release which have been shown to contribute considerably to toxicity.

\section{Acknowledgements}

This work is funded by the Science foundation Ireland's Research Frontiers Programme and Fiosraigh Scholarship Programme. This work was conducted under the framework of the INSPIRE programme, funded by the Irish Government's Programme for Research in Third Level Institutions, Cycle 4, National Development Plan 2007-2013, supported by the European Union Structural Fund. 


\section{Conflict of Interest}

The authors declare there are no conflicts of interest.

\section{References}

Adeyemi O. S, Faniyan T. O. 2014. Antioxidant status of rats administered silver nanoparticles orally. J Taibah Univ Med Sci. 9: 182-186

Aggarwal P, Hall J. B, McLeland C. B, Dobrovolskaia M. A, McNeill S. E. 2009. Nanoparticle interaction with plasma proteins as it relates to particle biodistribution, biocompatibility and therapeutic efficacy. Adv Drug Deliver Rev. 16: 428-437 
Arisawa S, Ishida K, Kameyama N, Ueyama J, Hattori A, Tatsumi Y, Hayashi H, Yano M, Hayashi K, Katano Y, Goto H, Takagi K Wakusawa S. 2009. Ursodeoxycholic acid induces glutathione synthesis through activation of PI3K/Akt pathway in HepG2 cells. Biochem Pharmacol. 77: 858866

Beer C, Foldjberg R, Hayashi Y, Sutherland D. S, Autrup H. 2012. Toxicity of silver nanoparticlesNanoparticle or silver ion? Toxicol Lett. 208: 286-292

Bouwmeester H, Dekkers S, Noordam M.Y, Hagens W. I, Bulder A. S, de Heer C, ten Voorde S. E, Wijnhoven S. W, Marvin H. J, Sips A. J. 2009. Review of health safety aspects of nanotechnologies in food production. Regul Toxicol Pharmacol. 53: 52-62

Casey A, Davoren M, Herzog E, Lyng F.M, Byrne H.J, Chambers G. 2007. Probing the interaction of single walled carbon nanotubes within cell culture medium as a precursor to toxicity testing. Carbon. 45: 34-40

Casey A, Herzog E, Lyng F.M, Byrne H.J, Chambers G, Davoren M. 2008 Single walled carbon nanotubes induce indirect cytotoxicity by medium depletion in A549 lung cells. Toxicol Lett. 179: $78-84$

Choi O, Deng K.K, Kim N-J, Ross Jr L, Surampalli R.Y, Hu Z. 2008. The inhibitor effects of silver nanoparticles, silver ions and silver chloride colloids on microbial growth. Water Res. 42: 3066-3074

Cohen J, Deloid G, Pyrgiotakis G, Demokritou P. 2013. Interactions of engineered nanomaterials in physiological media and implications for in vitro dosimetry. Nanotoxicology. 7: 417-431

Cohen J. M, Teeguarden J. G, Demokritou P. 2014. An integrated approach for the in vitro dosimetry of engineered nanomaterials. Part Fibre Toxicol. 11:20

Debruyne P. R, Bruyneel E. A, Li X, Zimber A, Gespach C, Mareel M. M. 2001. The role of bile acids in carcinogenesis. Mutat Res-Gen Mol M. 480-481: 359-369

Deschner E. E, Cohen B. I, Raicht R. F. 1981. Acute and chronic effect of dietary cholic acid on colonic epithelial cell proliferation. Digestion. 21: 290-296

European Commission. Commission recommendation of $18^{\text {th }}$ October 2011 on the definition of a nanomaterial text with EEA relevance. 2011. Retrieved on $12^{\text {th }}$ March, 2013 from http://ec.europa.eu/environment/chemicals/nanotech/index.htm\#top-page

European Medicines Agency. Orphacol: EPAR- Summary for the public. 2013. Retrieved on $20^{\text {th }}$ February, 2014 from http://www.ema.europa.eu/docs/en_GB/document_library/EPAR _Summary_for_the_public/human/001250/WC500150996.pdf

Gray J.J. 2004. The interaction of proteins with solid surfaces. Curr Opin Struct Biol. 14: 110-115

Gupta Mukherjee S, O’Claonadh N, Casey A, Chambers G. 2012. Comparative in vitro cytotoxicity study of silver nanoparticle on two mammalian cell lines. Toxicol In Vitro. 26: 238251 
Hadrup N, Lam H. R. 2014. Oral toxicity of silver ions, silver nanoparticles and colloidal silverA review. Regul Toxicol Pharm. 68: 1-7

Herzog E, Byrne H. J, Davoren M, Casey A, Duschl A, Oostingh G. J. 2009. Dispersion medium modulates oxidative stress response of human lung epithelial cells upon exposure to carbon nanomaterial samples. Toxicol Appl Pharmacol. 236: 276-281

Jeong G. N, Jo U. B, Ryu H. Y, Kim Y. S, Song K. S, Yu I. J. 2010. Histochemical study of intestinal mucins after administration of silver nanoparticles in Sprague-Dawley rats. Arch Toxicol. 84: $63-69$

Johnston H. J, Semmler-Behnke M, Brown D. M, Kreyling W. G, Tran L, Stone V. 2010. Evaluating the uptake and intracellular fate of polystyrene nanoparticles by primary and hepatocyte cell lines in vitro. Toxicol Appl Pharm. 242: 66-78

Kam N. S. W, Jessop T. C, Wender P. A, Dai H. J. 2004. Nanotube molecular transporters: Internalization of carbon nanotube-protein conjugates into mammalian cells. J Am Chem Soc. 126: 6850-6851

Kim S, Choi J. E, Choi J, Chung K. H, Park K, Yi J, Ryu D. Y. 2009. Oxidative stress dependent toxicity of silver nanoparticles in human hepatoma cells. Toxicol In Vitro. 23: 1076-1084

Kim S. K, Vaishali B, Lee E, Lee S, Lee Y. K, Kumar T. S, Moon H. T, Byun Y. 2006. Oral delivery of chemical conjugates of heparin and deoxycholic acid in aqueous formulation. Thromb Res. 117: 419-427

Kim Y. S, Kim J. S, Cho H. S, Rha D. S, Kim J. M, Park J. D, Choi B. S, Lim R, Chang H. K, Chung Y. H, Kwon I. H, Jeong J, Han B. S, Yu I. J. 2008. Twenty-eight day oral toxicity, genotoxicity, and gender related tissue distribution of silver nanoparticles in Sprague-Dawley rats. Inhalation Toxicol. 20: 575-583

Kim Y. S, Song M.Y, Park J. D, Song K. S, Ryu H. R, Chung Y. H, Chang H. K, Lee J. H, Oh K. H, Kelman B. J Hwang I. K, Yu I. J. 2010. Subchronic oral toxicity of silver nanoparticles. Part Fibre Toxicol. 7: 20

Kroll A, Pillukat M. H, Hahn D, Schnekenburger J. 2009. Current in vitro methods in nanoparticle risk assessment: limitations and challenges. Eur J Pharm Biopharm. 72: 370-377

Kumar P, Bohidar H.B. 2010. Aqueous dispersion stability of multi-carbon nanoparticles in anionic, cationic, neutral, bile salt and pulmonary surfactant solutions. Colloid Surface A. 361 (13): $13-24$

Lapenna D, Ciofani G, Festi D, Neri M, Pierdomenico S. D, Giamberardino M. A, Cuccurullo F. 2002. Antioxidant properties of ursodeoxycholic acid. Biochem Pharmacol. 64: 1661-1667

Lee Y, Nam J. H, Shim H. C, Byun Y. 2001. Conjugation of low-molecular-weight heparin to deoxycholic acid for the development of a new oral anticoagulant agent. Circulation. 104: 31163120 
Limbach L. K, Wick P, Manser P, Grass R. N, Bruinink A, Stark W. J. 2007. Exposure of engineered nanoparticles to human lung epithelial cells: influence of chemical composition and catalytic activity on oxidative stress. Environ Sci Technol. 41: 4158-4163

Liu J, Hurt R. H. 2010. Ion release kinetics and particles persistence in aqueous nanosilver colloids. Environ Sci Technol. 44: 2169-2175

Lynch I, Cedervall T, Lundqvist M, Cabaleiro-Lago C, Linse S, Dawson K.A. 2007. The nanoparticle-protein complex as a biological entity; a complex fluids and surface science challenge for the $21^{\text {st }}$ century. Adv Colloid Interfac. 134-135: $167-174$

Lynch I, Dawson K.A. 2008. Protein- nanoparticle interactions. Nano Today. 3: 40-47

Marcus S. N, Heaton K. W. 1988. Deoxycholic acid and the pathogenesis of gall stones. Gut. 29: $522-533$

Medicinenet, Med terms Medical Dictionary. Define biofluid. Retrieved on 8th August, 2014 from http://www.medterms.com/script/main/art.asp?articlekey $=38690$

Misra S. K, Dybowska A, Berhanu D, Luoma S. L, Valsami-Jones E. 2012. The complexity of nanoparticle dissolution and its importance in nanotoxicological studies. Sci Total Environ. 438: $225-232$

Mwilu S.K, El Badawy A.M, Bradham K, Nelson C, Thomas D, Scheckel K. G, Tolaymat T, Ma L, Rogers K. R. 2013. Changes in silver nanoparticles exposed to human synthetic stomach fluid: Effects of particle size and surface chemistry. Sci Total Environ. 447: 90-98

Nano and Other Emerging Technologies Blog. EC submits proposed nano food labelling regulation to WTO. 2013. Retrieved on $19^{\text {th }}$ February, 2014 from http://nanotech.lawbc.com/2013/09/articles/international/ec-submits-proposed-nano-foodlabeling-regulation-to-wto/

Navarro E, Piccapietra F, Wagner B, Marconi F, Kaegi R, Odzak N, Sigg L, Behra R. 2008. Toxicity of silver nanoparticles to Chlamydomonas reinhardtii. Environ Sci Technol. 42: 89598964

Nemmar A, Hoet P. H, Vanquickenborne B, Dinsdale D, Thomeer M, Hoylaerts M. F, Vanbilloen H, Mortelmans L, Nemery A. 2002. Passage of inhaled particles into the blood circulation in humans. Circulation. 105: 411-414

Ochsenkuhn T, Bayerdorffer E, Meining A, Schinkel M, Thiede C, Nussler V, Sackmann M, Hatz R, Neubauer A, Paumgartner G. 1999. Colonic mucosal proliferation is related to serum deoxycholic acid levels. Cancer. 85: 1664-1669

Perez M.J, Briz O. 2009. Bile-acid-induced cell injury and protection. World J Gastroenterol. 15 (14): 1677-1689

Poda A.R, Bednar A.J, Kennedy A.J, Harmon A, Hull M, Mitrano D. M, Ranville J. F, Steevens J. 2011. Characterisation of silver nanoparticles using flow-field flow fractionation interfaced to inductively coupled plasma mass spectrometry. J Chromat. A. 1218 (27): 4219-4225 
Premanathan M, Karthikayan K, Jeyasubramanian K, Manivannan G. 2011. Selective toxicity of $\mathrm{ZnO}$ nanoparticles toward Gram-positive bacteria and cancer cells by apoptosis through lipid peroxidation. Nanomed-Nanotechnol. 7: 184-192

Rai M, Yadav A, Gade A. 2009. Silver nanoparticles as a new generation of antimicrobials. Biotecnol Adv. 27: 76-83

Renwick L.C, Brown D, Clouter A, Donaldson K. 2004. Increased inflammation and altered macrophage chemotactic responses caused by two ultrafine particle types. Occup Environ Med. 61: $442-446$

Semmler-Behnke M, Kreyling W. G, Lipka J, Fertsch S, Wenk A, Takenaka S, Schmid G, Brandau W. 2008. Biodistribution of 1.4- and 18-nm gold nanoparticles in rats. Small. 4: 2108-2111

Shahare B, Yashpal M. 2013. Toxic effects of repeated oral exposure of silver nanoparticles on small intestine mucosa of mice. Toxicol Mech Methods. 23: 161-167

Sozar N, Kokini J.L. 2009. Nanotechnology and its applications in the food sector. Trends Biotechnol. 27: 82-9

Studer A. M, Limbach L. K, Van Duc L, Krumeich F, Athanassiou E. K, Gerber L. C, Moch H, Stark W. J. 2010. Nanoparticle cytotoxicity depends on intracellular solubility: comparison of stabilized copper metal and degradable copper oxide nanoparticles. Toxicol Lett. 197: 169-174

Teeguarden J. G, Hinderliter P. M, Orr G, Thrall B. D, Pounds J. G. 2007. Particokinetics in vitro: dosimetry considerations for in vitro nanoparticle toxicity assessments. Toxicol Sci. 95: 300-312

Wang F, Yu L, Monopoli M.P, Sandin P, Mahon E, Salvati A, Dawson K. A. 2013. The biomolecular corona is retained during nanoparticle uptake and protects the cells form the damage induced by cationic nanoparticles until degraded in lysosomes. Nanomed-Nanotechnol. 9: 11591168

Xia T, Kovochich M, Brant J, Hotze M, Sempf J, Oberley T, Sioutas C, Yeh J. I, Wiesner M. R, Nel A. E. 2006. Comparison of the abilities of ambient and manufactured nanoparticles to induce cellular toxicity according to an oxidative stress paradigm. Nano Lett. 6: 1794-1807

Zhai H.J, Sun D.W, Wang H.S. 2006. Catalytic properties of silica/silver nanocomposites. $J$ Nanosci Nanotechnol. 6: 1968-1972

Zhao B, Sun L, Zhang W, Wang Y, Zhu J, Zhu X, Yang L, Li C, Zhang Z, Zhang Y. 2014. Secretion of intestinal goblet cells: A novel excretion pathway of nanoparticles. NanomedNanotechnol. 10: 893-849 
Table 1 Table of Zeta Potential results for three concentrations of AgNps 3.91, 15.6 and $62.5 \mu \mathrm{g} / \mathrm{ml}$ dispersed in different cell culture media and in the presence of different biofluid components. Data expressed as average value $\pm \mathrm{SD}$ of three individual experiments.

\begin{tabular}{|l|l|l|l|}
\hline & $62.5 \mu \mathrm{g} / \mathrm{ml}$ & $15.6 \mu \mathrm{g} / \mathrm{ml}$ & $3.9 \mu \mathrm{g} / \mathrm{ml}$ \\
\hline AgNP Only & $-15.5 \pm 1.2 \mathrm{mV}$ & $-31.2 \pm 0.9 \mathrm{mV}$ & $-22.1 \pm 6.6 \mathrm{mV}$ \\
& & & \\
\hline AgNP RPMI & -473.7 & $-380 \pm$ & $-221 \pm$ \\
& $\pm 50.8 \mathrm{mV}$ & $121.1 \mathrm{mV}$ & $117.2 \mathrm{mV}$ \\
\hline AgNP DMEM & $-7.9 \pm 5.1 \mathrm{mV}$ & $1.9 \pm 3.4 \mathrm{mV}$ & $-11.2 \pm 7.2 \mathrm{mV}$ \\
\hline AgNP 1mM Cholic Acid DMEM & $-7.1 \pm 6.9 \mathrm{mV}$ & $-2.56 \pm 3.4 \mathrm{mV}$ & $-27.6 \pm 5 \mathrm{mV}$ \\
\hline $\begin{array}{l}\text { AgNP 0.125mM Deoxycholic Acid } \\
\text { DMEM }\end{array}$ & $-4.9 \pm 9.8 \mathrm{mV}$ & $-12.1 \pm 5 \mathrm{mV}$ & $-5.5 \pm 8.9 \mathrm{mV}$ \\
\hline AgNP 50 $\mu$ M UDCA DMEM & $-6.6 \pm 2.3 \mathrm{mV}$ & $-8.1 \pm 6.4 \mathrm{mV}$ & $-6 \pm 5 \mathrm{mV}$ \\
\hline
\end{tabular}


Table 2 Calculated $\mathrm{IC}_{50}$ values $(\mu \mathrm{g} / \mathrm{ml})$ resulting from exposure to $\mathrm{AgNps}$ for the $\mathrm{AB}$ and MTT assays in the HepG-2 and Hep2 cell lines. * Denotes lethal dose less than the lowest exposure concentration. $\mathrm{IC}_{50}$ values were calculated from the average response of three independent experiments fitted to a sigmoidal curve and a four parameter logistic model used to calculate Inhibitory Concentration $\left(\mathrm{IC}_{50}\right)$ with a $(\mathrm{p}<0.05)$

\begin{tabular}{|l|l|l|l|l|l|l|l|l|}
\hline Cell Line & \multicolumn{9}{|l|}{ AB assay IC $50(\mu \mathrm{g} / \mathrm{ml})$} & \multicolumn{3}{l|}{ MTT assay IC $50(\mu \mathrm{g} / \mathrm{ml})$} \\
\hline & $24 \mathrm{hr}$ & $48 \mathrm{hr}$ & $72 \mathrm{hr}$ & $96 \mathrm{hr}$ & $24 \mathrm{hr}$ & $48 \mathrm{hr}$ & $72 \mathrm{hr}$ & $96 \mathrm{hr}$ \\
\hline HepG-2 & 5.5 & 7.8 & 5.5 & 4.2 & 119.51 & 45.34 & 44.59 & 49.2 \\
\hline HepG-2 + UDCA & 6.3 & 9.1 & 5.3 & 5.7 & 135.06 & 66.52 & 31.81 & 10.97 \\
\hline HepG-2 + CA & 4.03 & 6.24 & 4.78 & 7.94 & 0.0004 & 0.0003 & 0.001 & 215.48 \\
\hline HepG-2 + DCA & 4.28 & 6.49 & 2.99 & 6.24 & 1389.3 & 746.29 & 0.002 & 0.003 \\
\hline Hep2 & 45.06 & 31.58 & 8.8 & 91.9 & 388.39 & 157 & 2.19 & 43.41 \\
\hline Hep2 + UDCA & 439.16 & 4.25 & 0.27 & 0.94 & 0.0007 & $<3.91^{*}$ & $<3.91^{*}$ & $<3.91^{*}$ \\
\hline
\end{tabular}




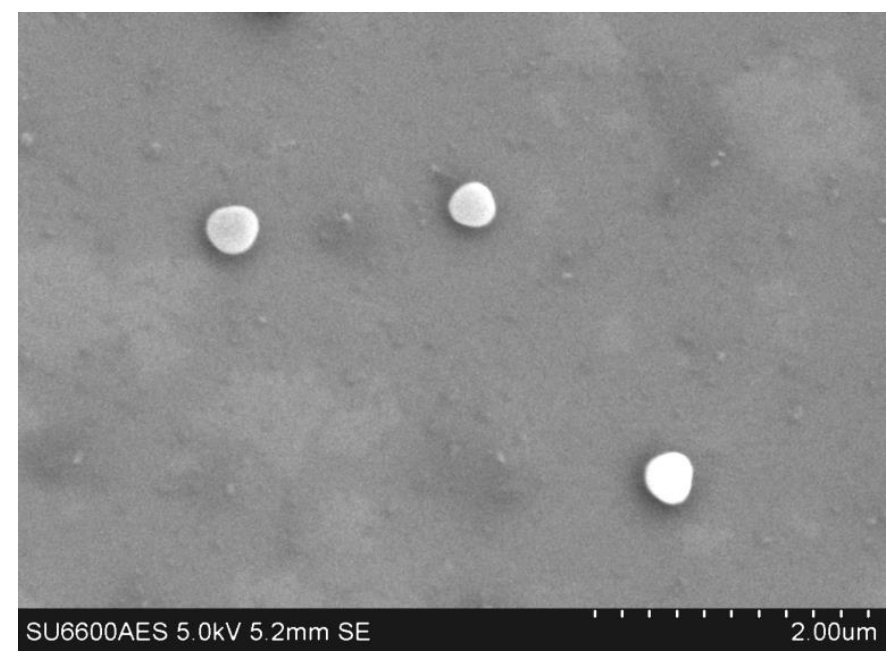

Figure $1 \mathrm{SEM}$ micrograph at scale bar of $2 \mu \mathrm{m}$ image pristine AgNP dispersed in ethanol to a concentration of $0.625 \mu \mathrm{g} / \mathrm{ml}$ by sonication using Ultrasonic Processor tip.

(a)

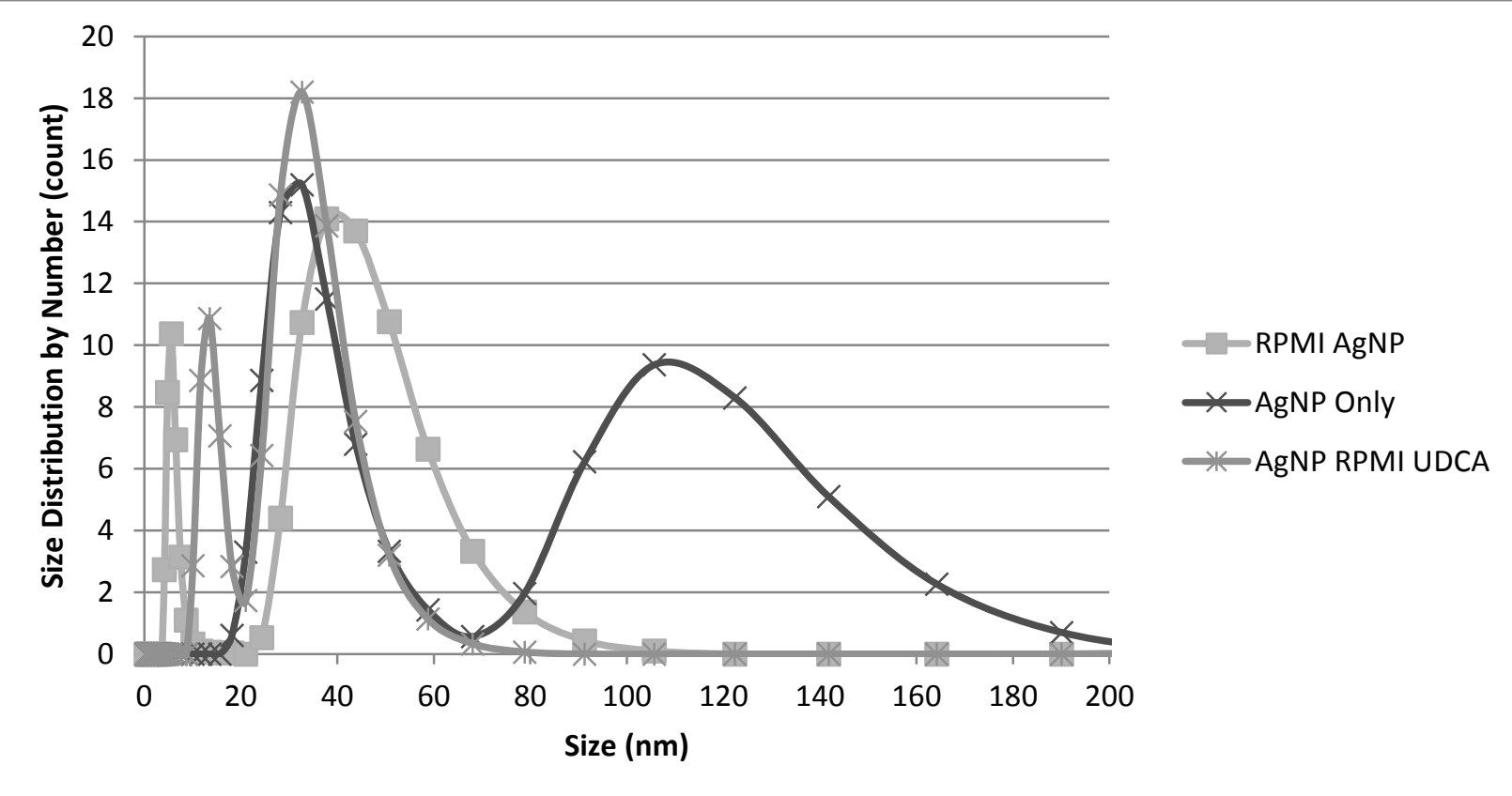


(b)
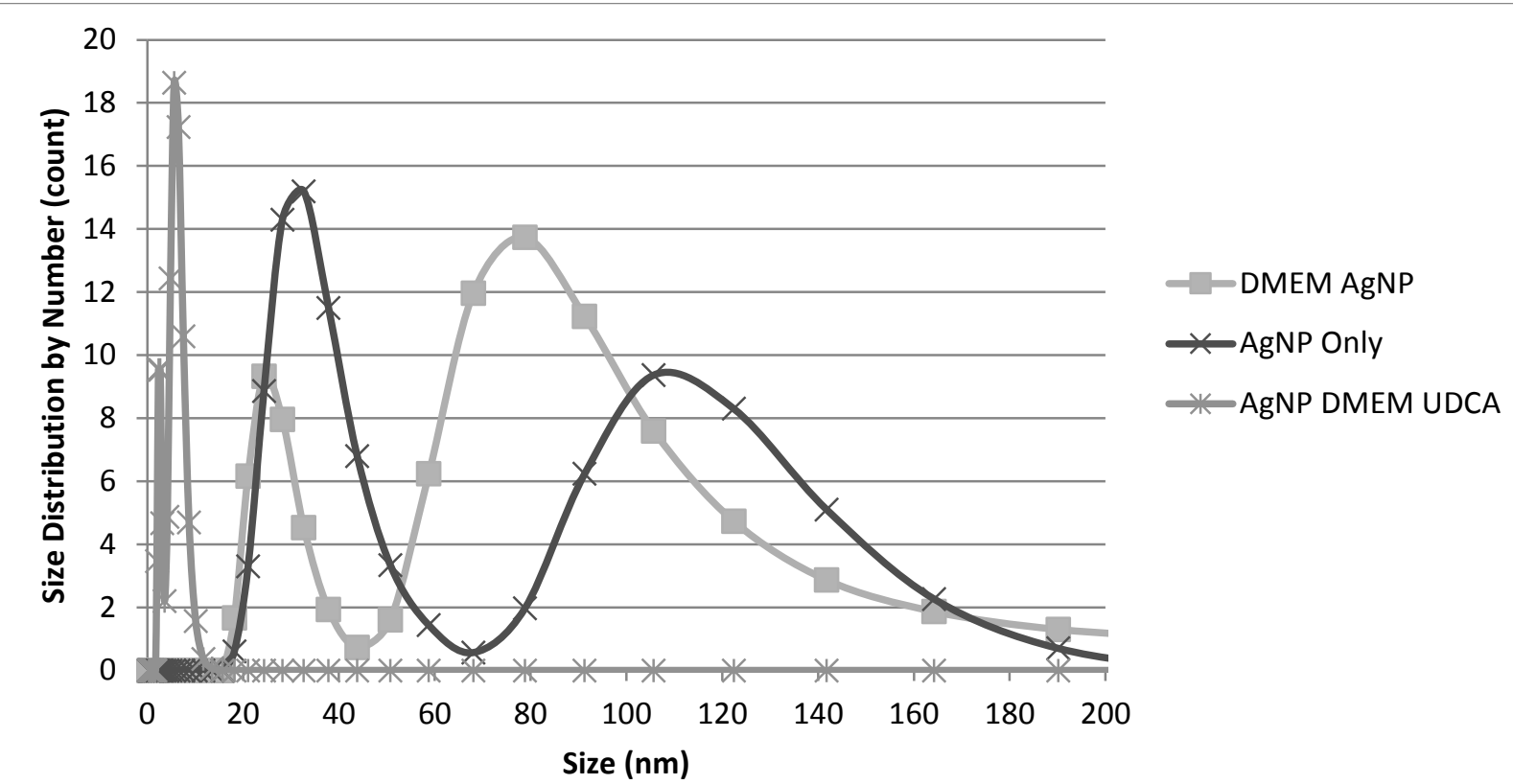

(c)

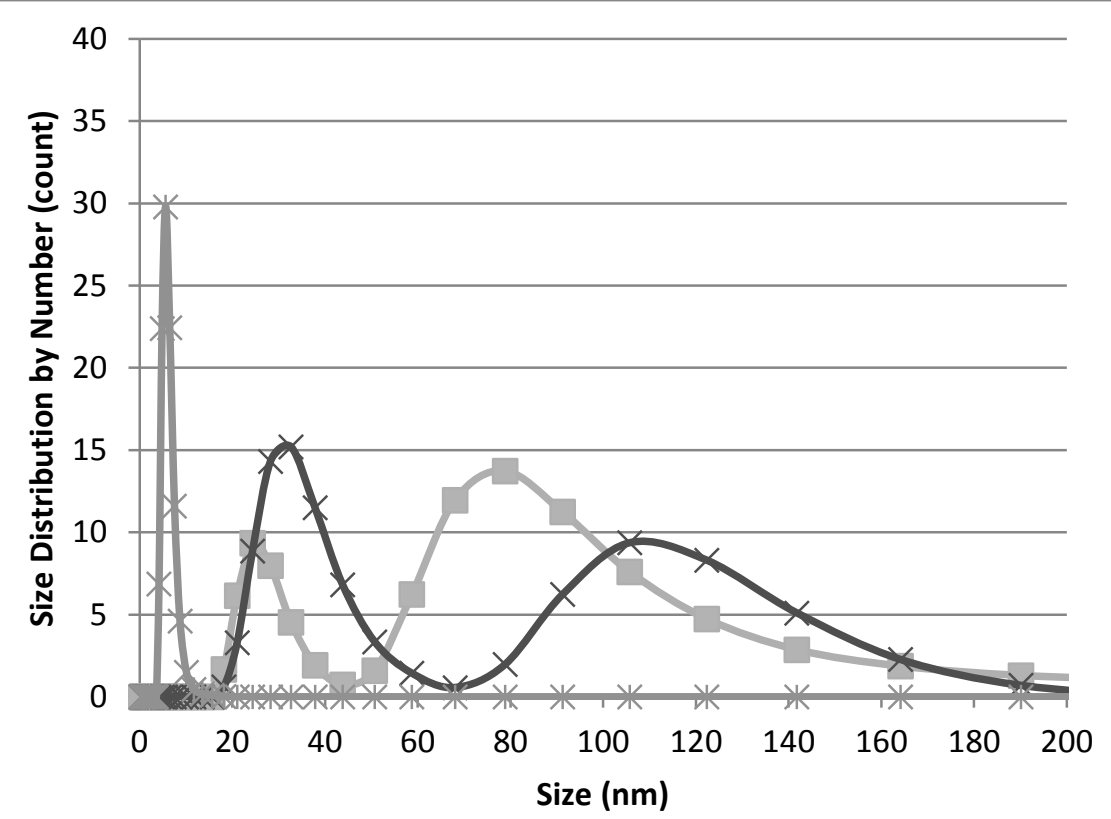

- DMEM AgNP

-AgNp Only

*AgNP DMEM Cholic Acid 
(d)

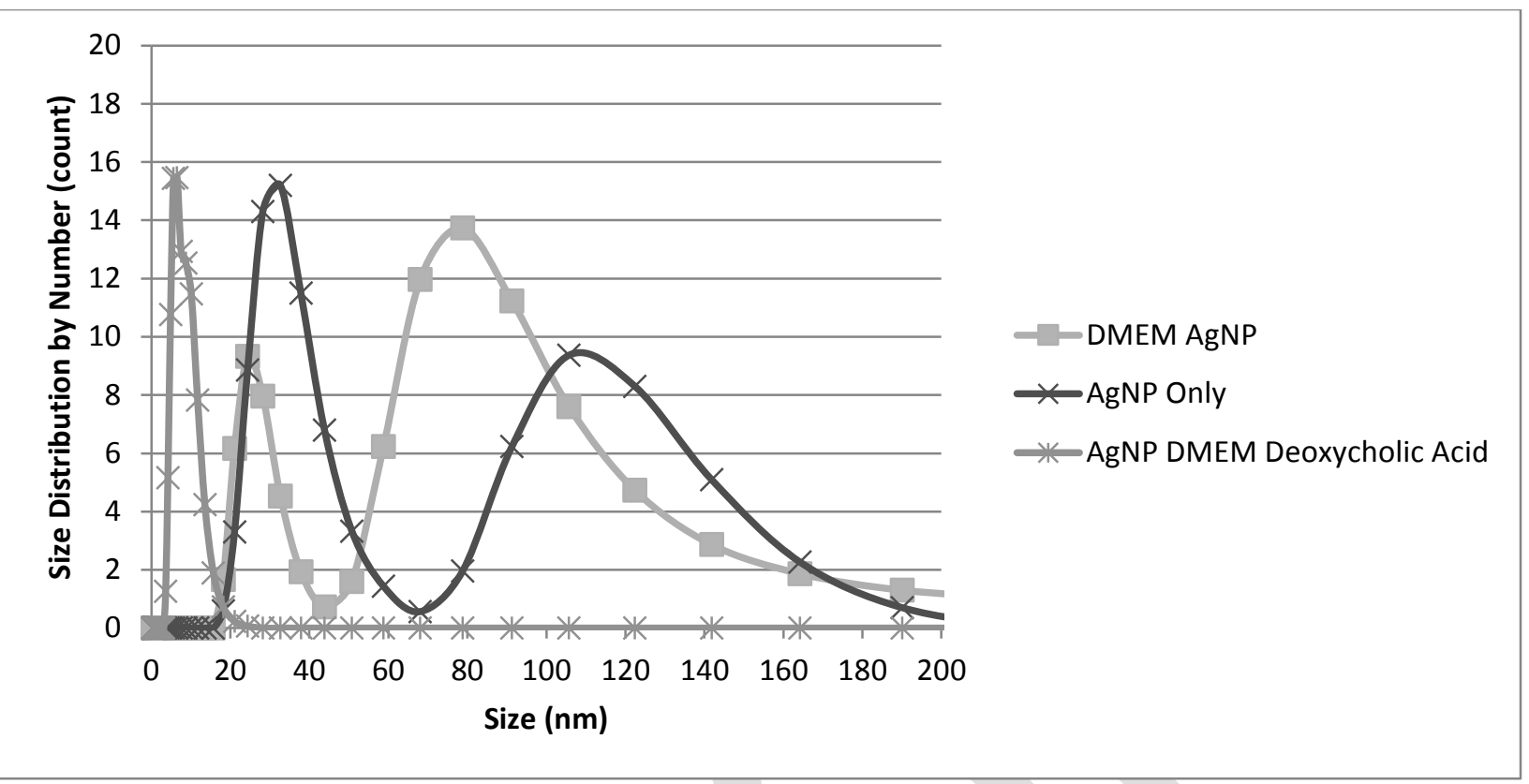

Figure 2 (a) - (d) Dynamic Light Scattering size (nm) particle number (count) distribution plot of $\operatorname{AgNP}(15.6 \mu \mathrm{g} / \mathrm{ml})$ dispersed in media, $\mathrm{dH}_{2} \mathrm{O}$ and in the presence of (a) UDCA (RPMI), (b) UDCA (DMEM), (c) CA and (d) DCA. Data presented is the average of three individual experiments

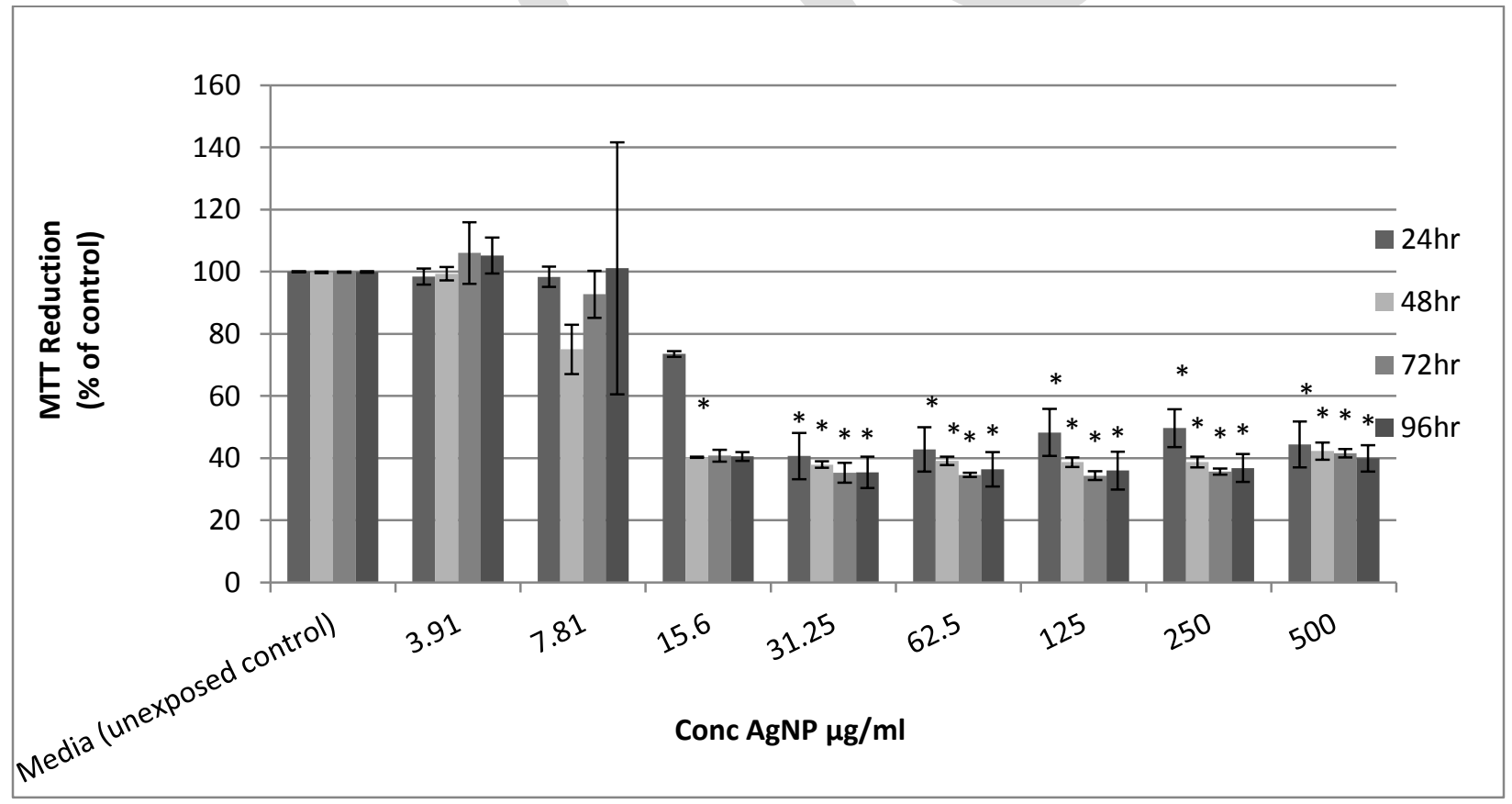

Figure 3 Cytotoxicity of AgNP in HepG-2 cells after 24, 48, 72, and 96hr exposures as determined by the MTT assay. Data expressed as percentage of control mean \pm SD of three individual experiments. $*$ denotes a statistically significant $(\mathrm{p}<0.01)$ difference from the unexposed control 


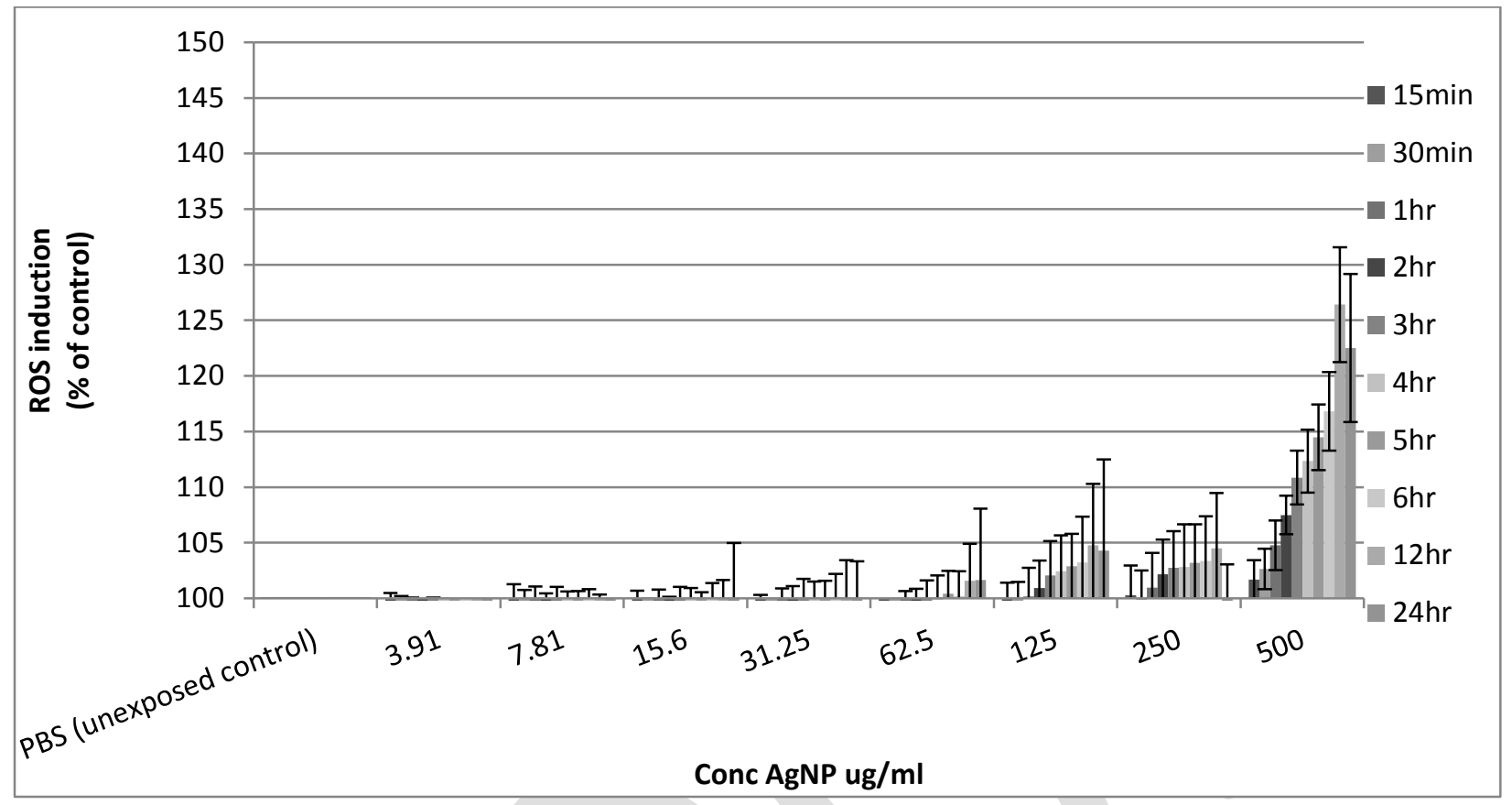

Figure 4 ROS generation in HepG-2 cells after different time points of AgNP exposure. Data expressed as percentage of control mean $\pm \mathrm{SD}$ of eight independent experiments.

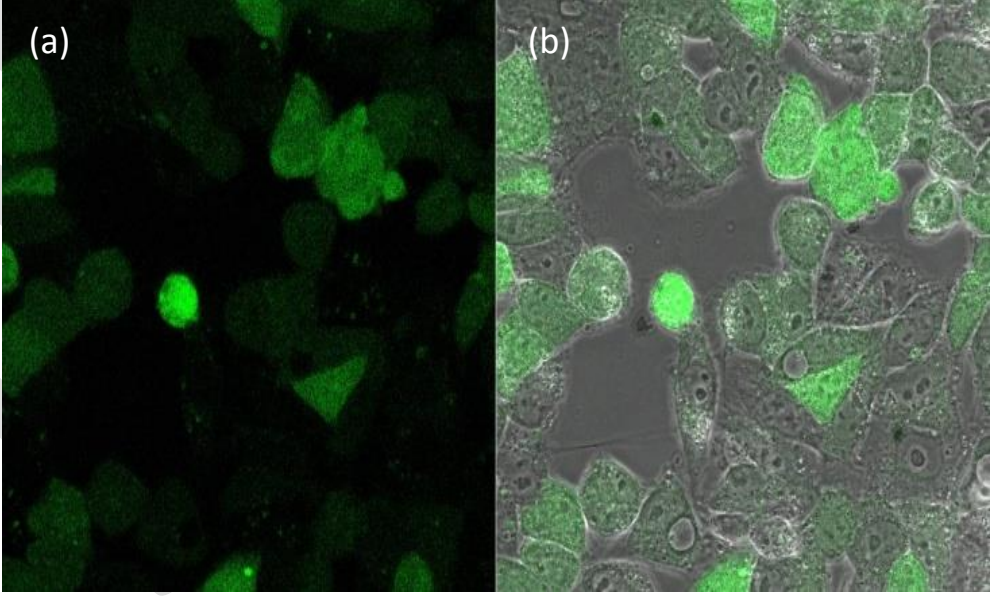

Figure 5 Confocal image (x40) of cells exposed to $31.25 \mu \mathrm{g} / \mathrm{ml}$ AgNP suspended in cell culture media. Image taken on a Zeiss 510 LSM confocal microscope with an argon ion laser, excitation $488 \mathrm{~nm}$ using a band pass filter 505-530nm to detect DCF. (a) LSM image demonstrating intracellular ROS, (b) overlay of LSM and brightfield image. 


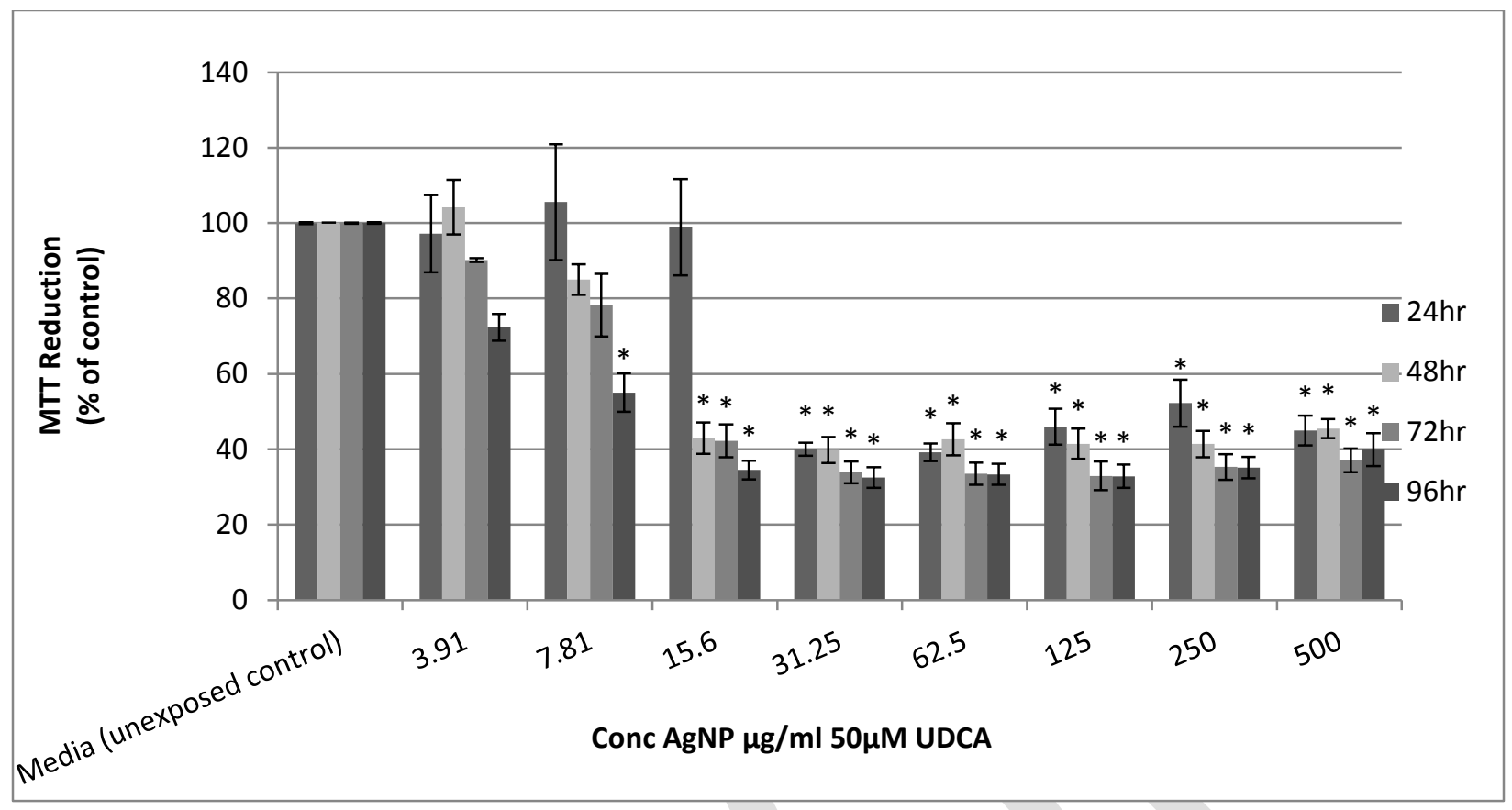

Figure 6 Cytotoxicity of AgNP in HepG-2 cells with added UDCA after 24, 48, 72 and 96hr exposures as determined by the MTT assay. Data expressed as percentage of control mean \pm SD of three independent experiments. * denotes a statistically significant $(\mathrm{p}<0.01)$ difference from the unexposed control

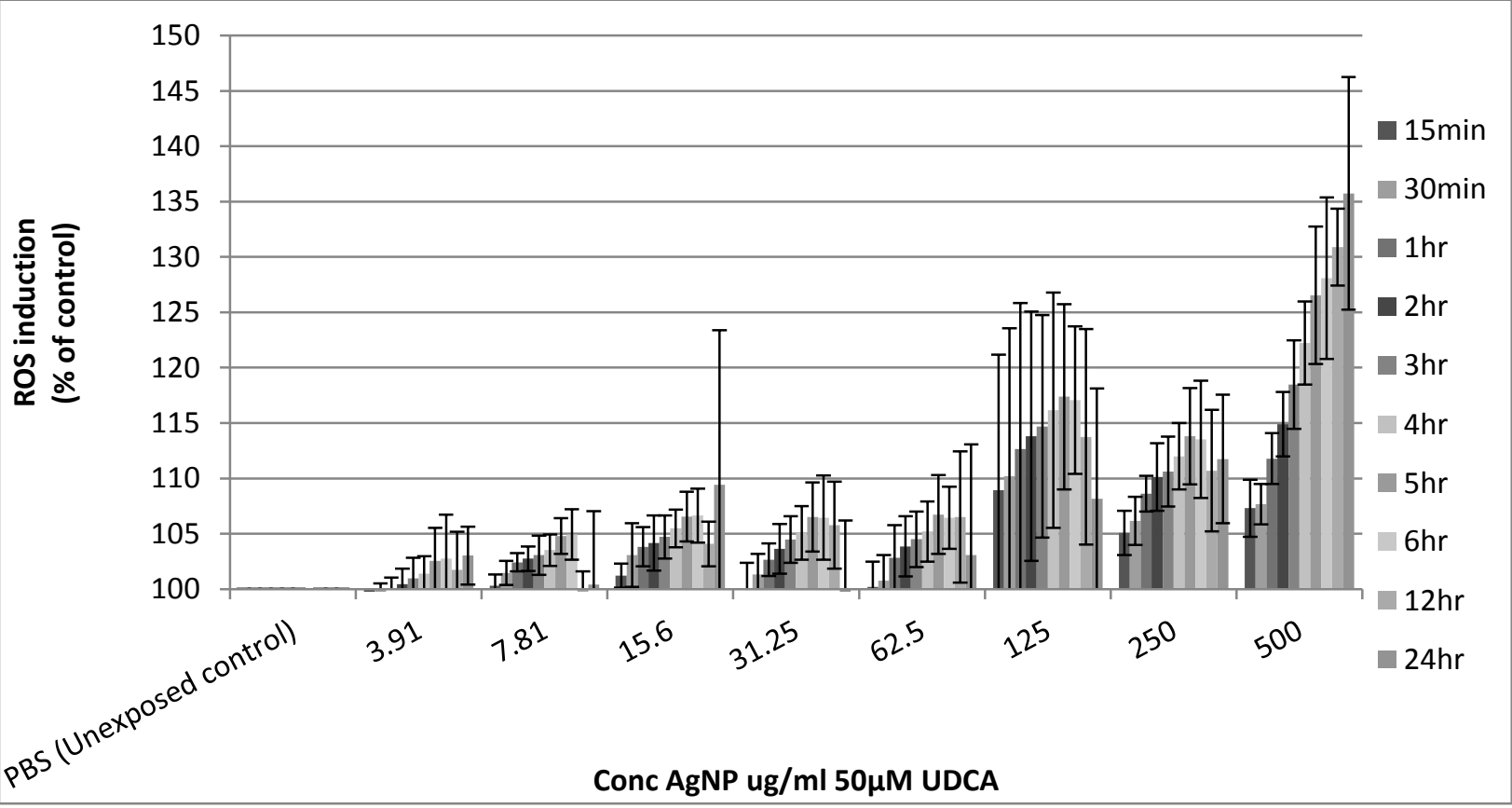


Figure 7 ROS generation in HepG-2 cells after different time points of AgNP exposure in the presence of UDCA. Data expressed as percentage of control mean \pm SD of eight independent experiments.

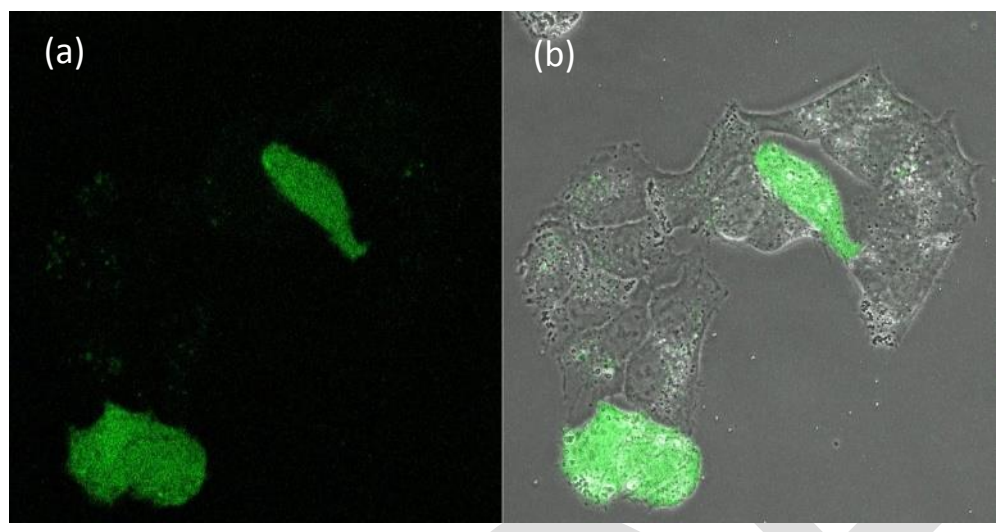

Figure 8 Confocal image (x40) of cells exposed to $31.25 \mu \mathrm{g} / \mathrm{ml}$ AgNP suspended in cell culture media in the presence of UDCA. Image taken on a Zeiss 510 LSM confocal microscope with an argon ion laser, excitation 488nm using a band pass filter 505-530nm to detect DCF. (a) LSM image demonstrating intracellular ROS, (b) overlay of LSM and brightfield image.

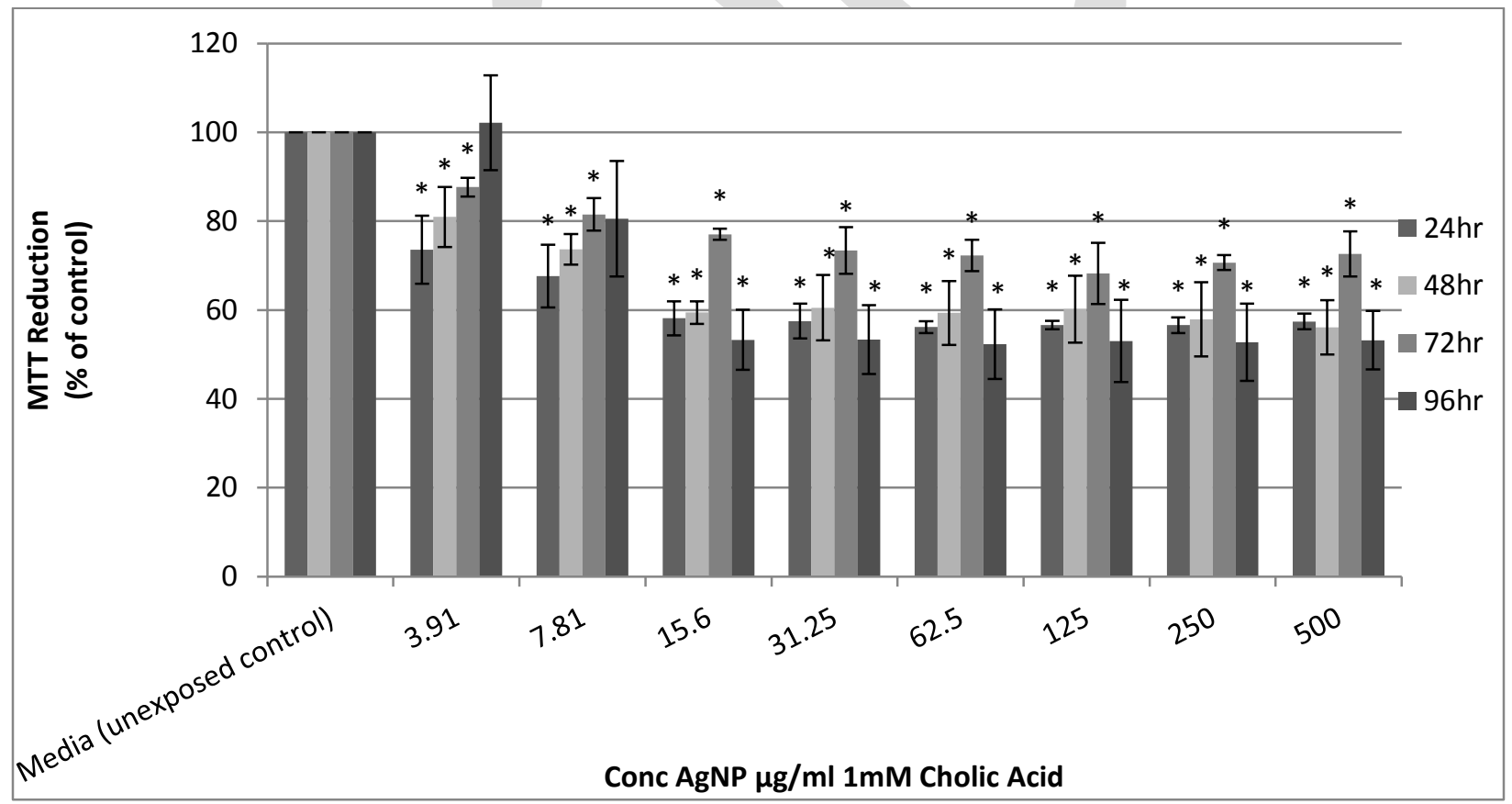

Figure 9 Cytotoxicity of AgNP in HepG-2 cells with added CA after 24, 48, 72, and 96hr exposures as determined by the MTT assay. Data expressed as percentage of control mean \pm SD of three independent experiments. * denotes a statistically significant $(\mathrm{p}<0.01)$ difference from the unexposed control 


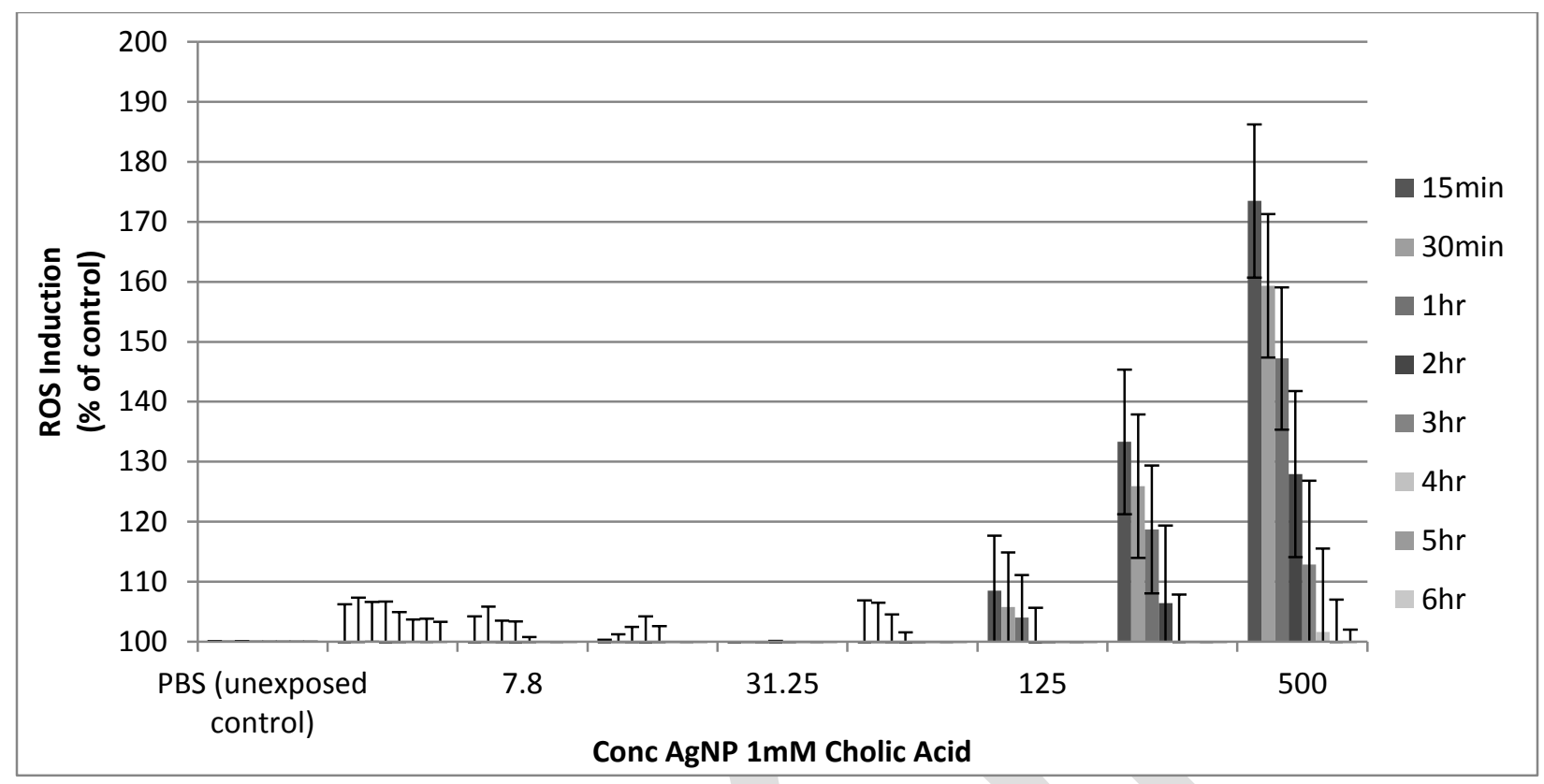

Figure 10 ROS generation in HepG-2 cells after different time points of AgNP exposure in the presence of CA. Data expressed as percentage of control mean $\pm \mathrm{SD}$ of eight independent experiments.

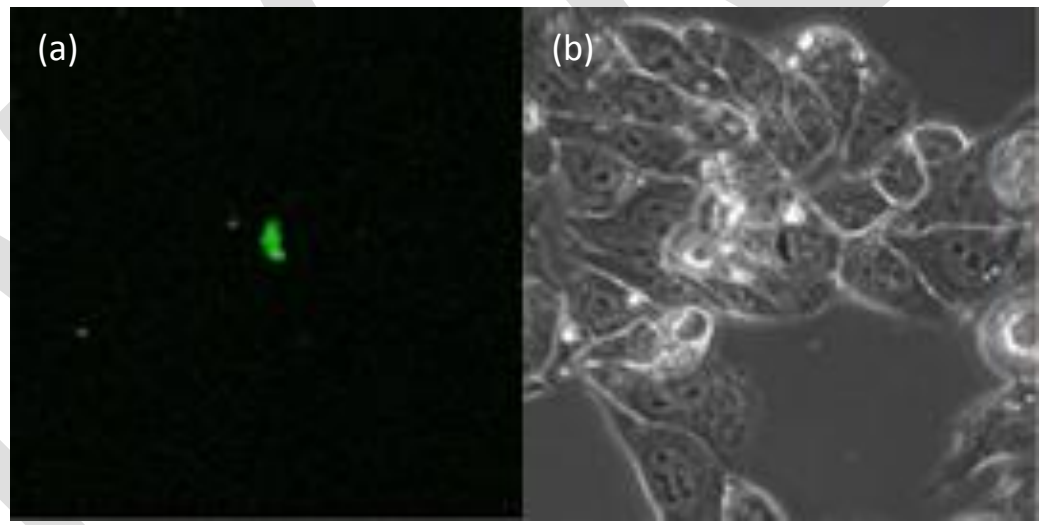

Figure 11 Confocal image (x40) of cells exposed to $31.25 \mu \mathrm{g} / \mathrm{ml}$ AgNP suspended in cell culture media in the presence of CA. Image taken on a Zeiss 510 LSM confocal microscope with an argon ion laser, excitation $488 \mathrm{~nm}$ using a band pass filter $505-530 \mathrm{~nm}$ to detect DCF. (a) LSM image demonstrating intracellular ROS, (b) overlay of LSM and brightfield image. 


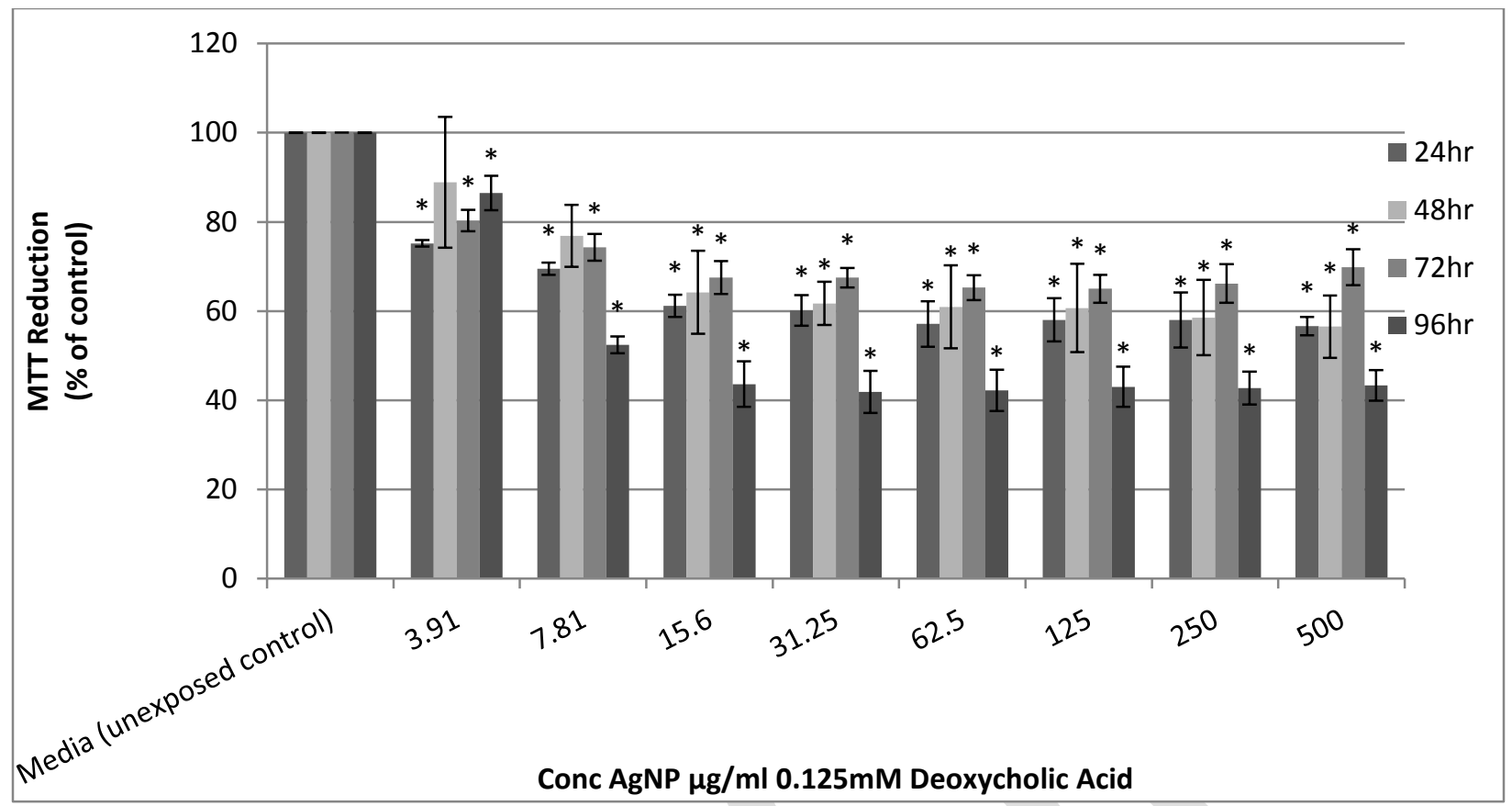

Figure 12 Cytotoxicity of AgNP in HepG-2 cells with added DCA after 24, 48, 72, and 96hr exposures as determined by the MTT assay. Data expressed as percentage of control mean \pm SD of three independent experiments. * denotes a statistically significant $(\mathrm{p}<0.01)$ difference from the unexposed control

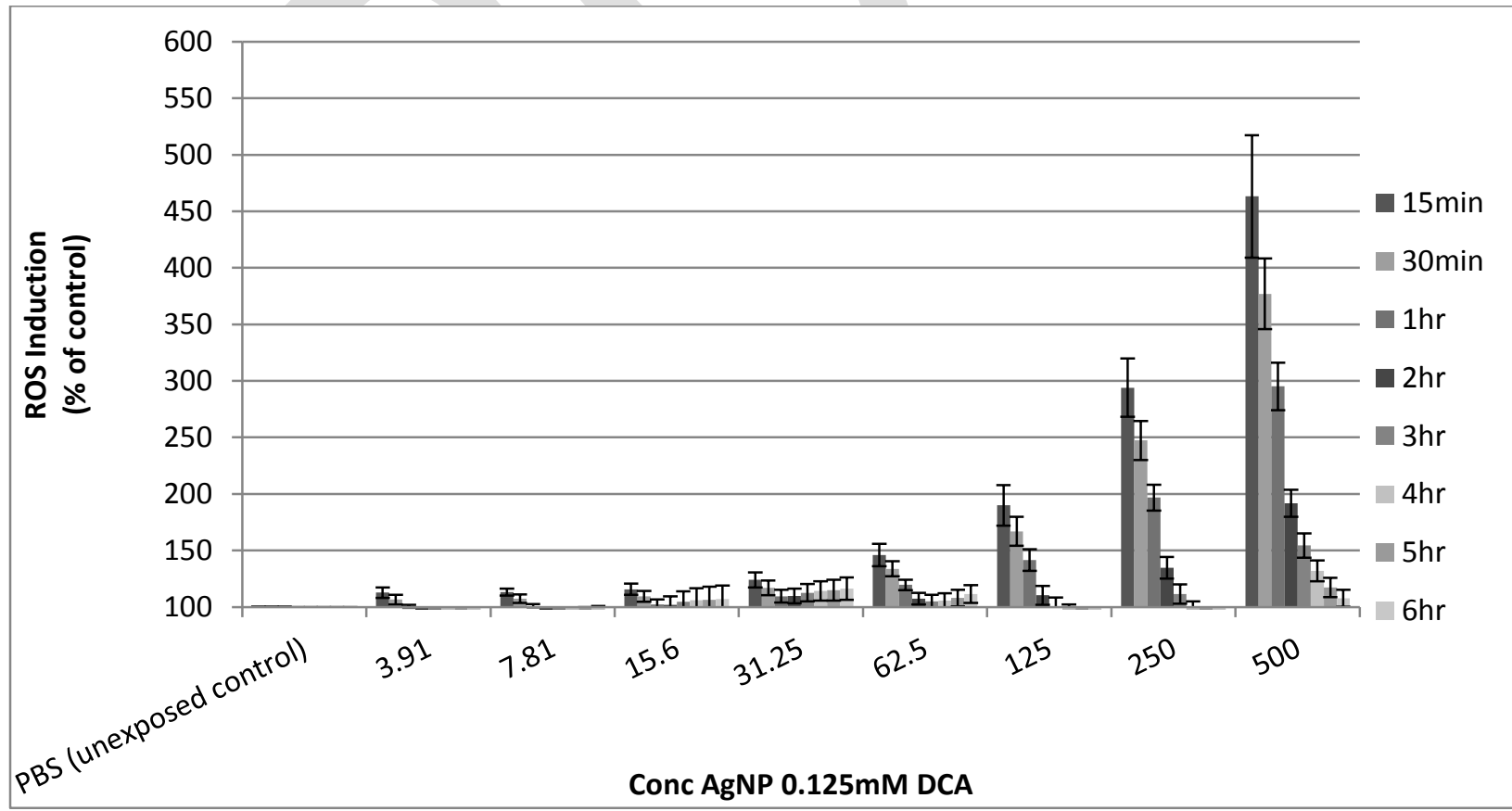


Figure 13 ROS generation in HepG-2 cells after different time points of AgNP exposure in the presence of DCA. Data expressed as percentage of control mean \pm SD of eight independent experiments.

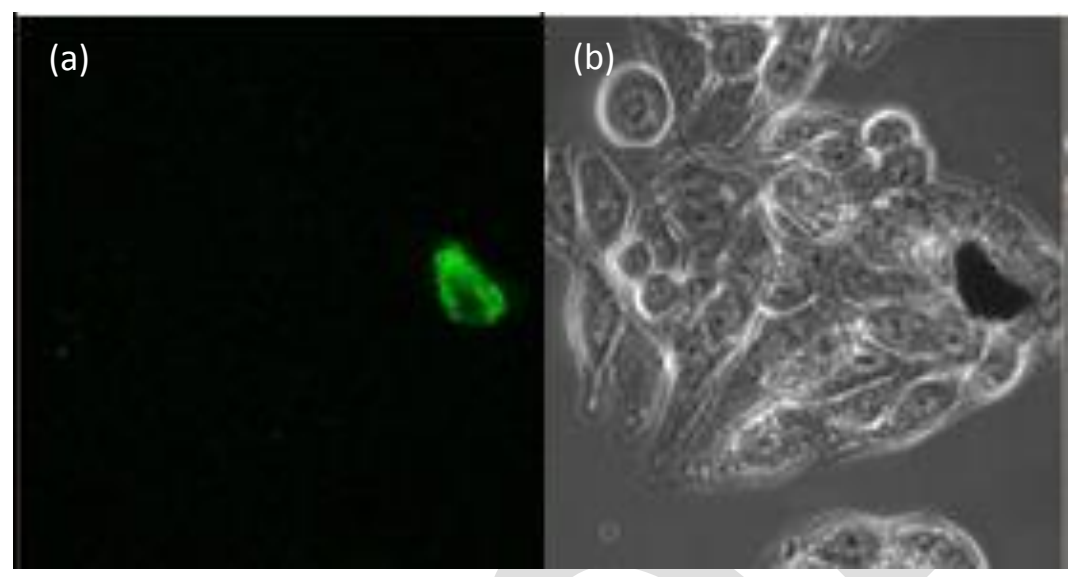

Figure 14 Confocal image (x40) of cells exposed to $31.25 \mu \mathrm{g} / \mathrm{ml}$ AgNP suspended in cell culture media in the presence of DCA. Image taken on a Zeiss 510 LSM confocal microscope with an argon ion laser, excitation 488nm using a band pass filter 505-530nm to detect DCF. (a) LSM image demonstrating intracellular ROS, (b) overlay of LSM and brightfield image.

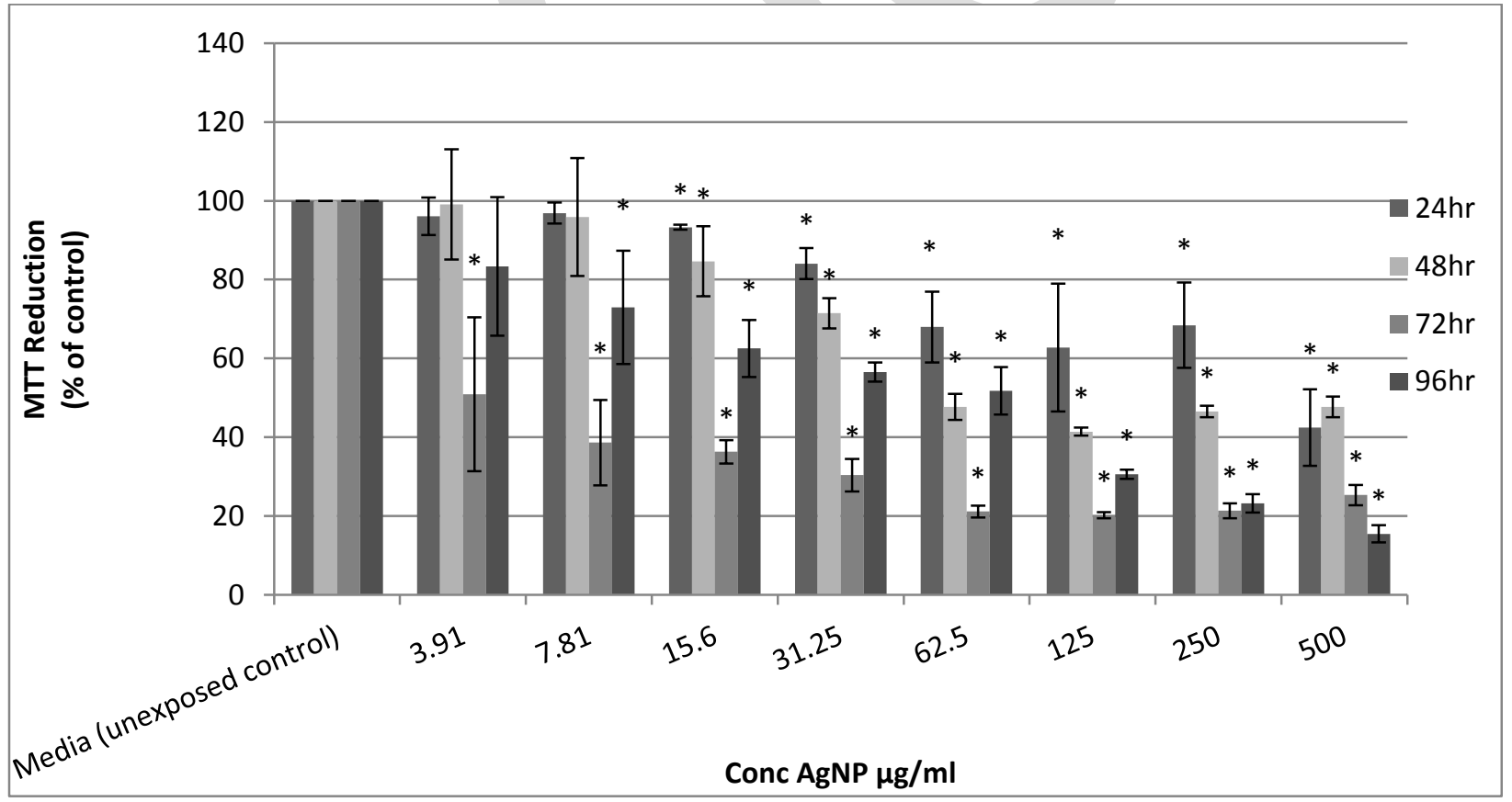

Figure 15 Cytotoxicity of AgNP to Hep2 cells after 24, 48, 72 and 96hr exposure as determined by the MTT assay. Data expressed as percentage of control mean \pm SD of three independent experiments. $*$ denotes a statistically significant $(\mathrm{p}<0.01)$ difference from the unexposed control 


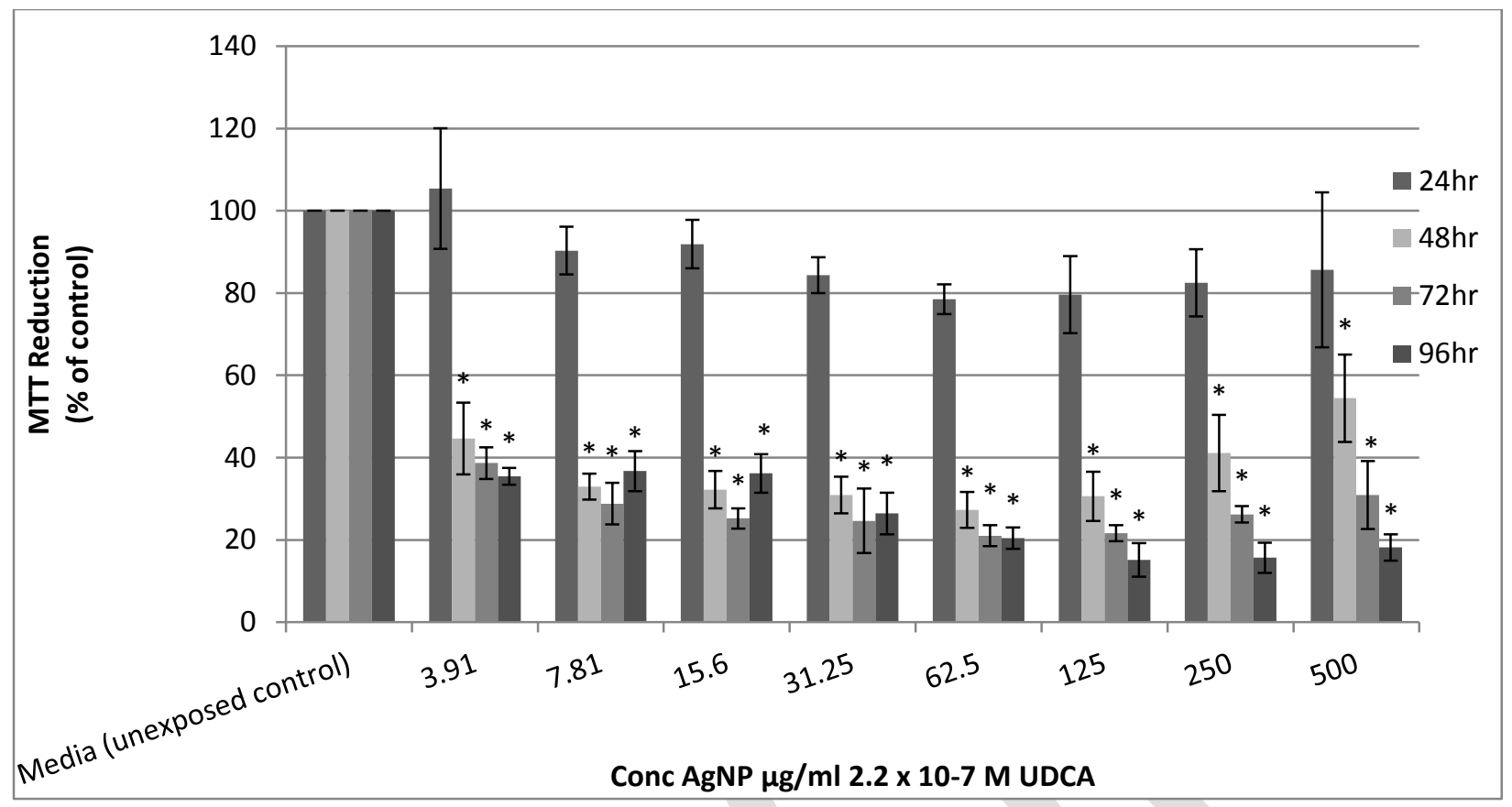

Figure 16 Cytotoxicity of AgNP to Hep2 cells with added UDCA after 24, 48, 72 and 96hr exposures as determined by the MTT assay. Data expressed as percentage of control mean \pm SD of three independent experiments. * denotes a statistically significant $(\mathrm{p}<0.01)$ difference from the unexposed control

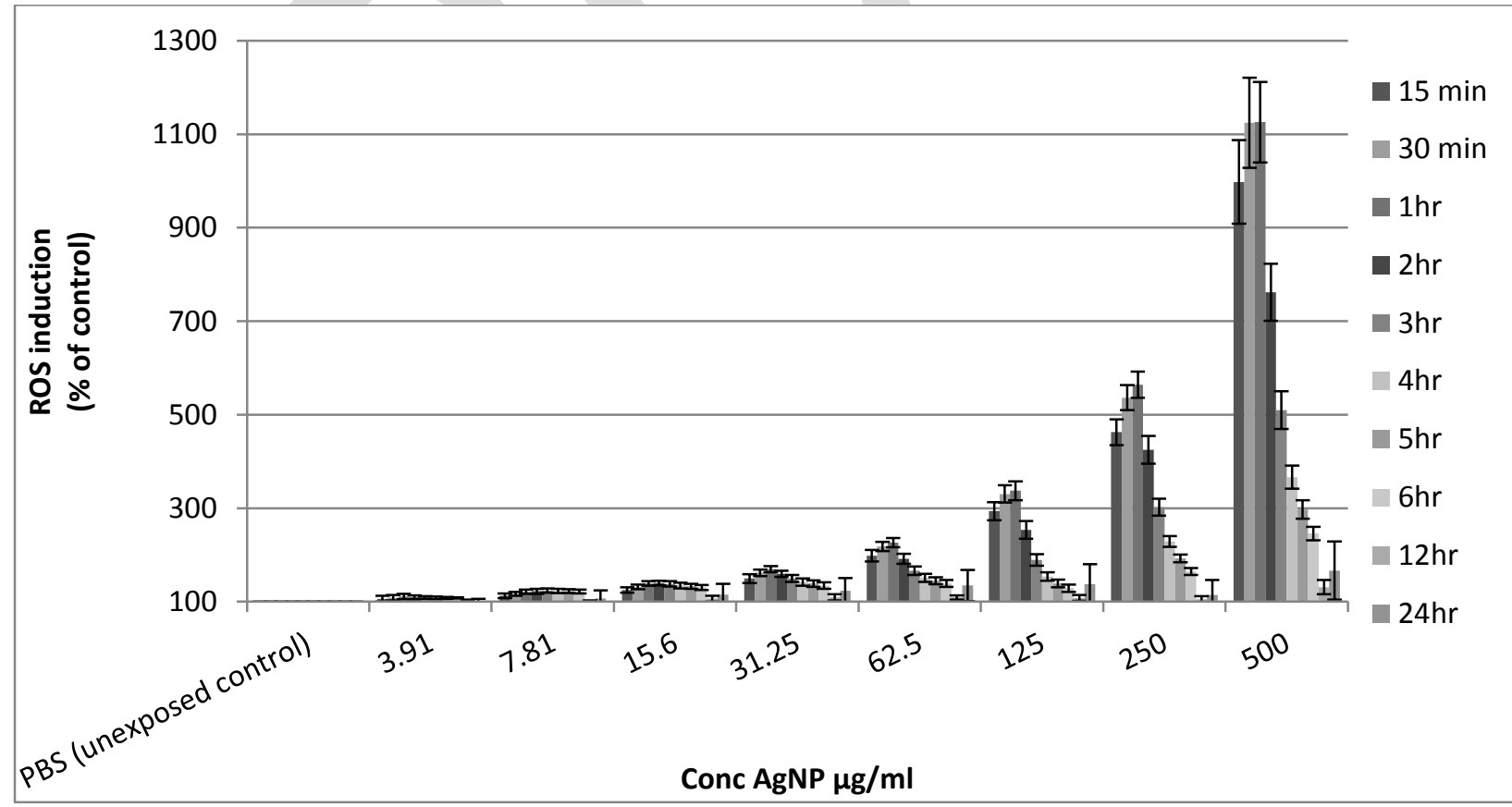

Figure 17 ROS generation in Hep2 cells after different time points of AgNP exposure. Data expressed as percentage of control mean \pm SD of eight independent experiments 


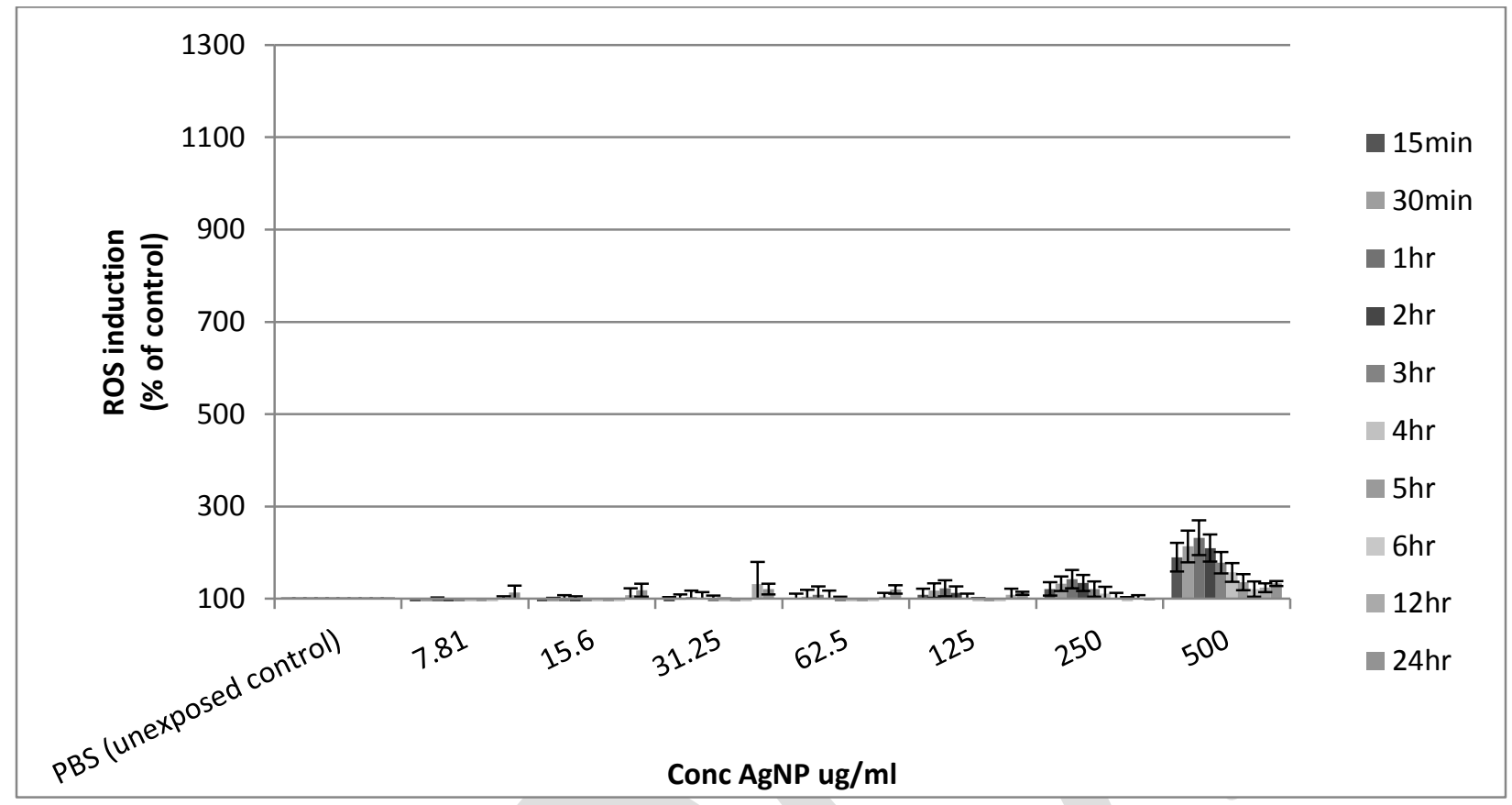

Figure 18 ROS generation in Hep2 cells after different time points of AgNP exposure in the presence of UDCA. Data expressed as percentage of control mean \pm SD of eight independent experiments 